\title{
Do we need a global VAR model to forecast inflation and output in South
}

\section{Africa?}

Annari de Waal, Reneé van Eyden ${ }^{* *}$ and Rangan Gupta ${ }^{* * *}$

02 April 2015

\begin{abstract}
This study determines whether the global vector autoregressive (GVAR) approach provides better forecasts of key South African variables than a vector error correction model (VECM) and a Bayesian vector autoregressive (BVAR) model augmented with foreign variables. The paper considers both a small GVAR model and a large GVAR model in determining the most appropriate model for forecasting South African variables. We compare the recursive out-ofsample forecasts for South African GDP and inflation from six types of models: a general 33country (large) GVAR, a customised small GVAR for South Africa, a VECM for South Africa with weakly exogenous foreign variables, a BVAR model, autoregressive (AR) models and random walk models. The results show that the forecast performance of the large GVAR is generally superior to the performance of the customised small GVAR for South Africa. The forecasts of both the GVAR models tend to be better than the forecasts of the augmented VECM, especially at longer forecast horizons. Importantly however, on average, the BVAR model performs the best when it comes to forecasting output, while the AR(1) model outperforms all the other models in predicting inflation. We also conduct ex ante forecasts from the BVAR and AR(1) models over 2010:Q1-2013:Q4, to highlight their ability to track turning points in output and inflation respectively.
\end{abstract}

\section{JEL Classification Codes: C51, C53}

Keywords: South Africa, global vector autoregressive (GVAR) model, Bayesian vector autoregressive (BVAR) model, forecasting

\footnotetext{
* Lecturer in the Department of Economics, University of Pretoria, South Africa. Annari de Waal acknowledges financial support from the Commonwealth Scholarship Commission in the UK and the Cambridge Commonwealth Trust.

** Professor in the Department of Economics, University of Pretoria.

*** Corresponding author. Professor in the Department of Economics, University of Pretoria. Email: rangan.gupta@up.ac.za.
} 


\section{Introduction}

The global vector autoregressive (GVAR) approach to macroeconomic modelling is a multicountry approach, with a global trade matrix that links individual country models. By allowing for international trade linkages, it is possible to investigate the transmission of shocks from one country to another. GVAR forecasts of domestic and foreign variables allow for these global interaction channels. In our study, we want to determine whether it is necessary to use a GVAR model when forecasting key domestic variables for South Africa or whether a country-specific vector error correction model (VECM) augmented with foreign variables, known as a VECX*, or a Bayesian vector autoregressive (BVAR) model also augmented with foreign variables, for South Africa would suffice.

We furthermore want to establish whether the GVAR model should include the standard 33 countries (Dées, Di Mauro, Pesaran \& Smith [henceforth DDPS], 2007; Dées, Holly, Pesaran \& Smith [henceforth DHPS], 2007) or whether it could include only a small subset of countries the most important trading partners of South Africa - when forecasting domestic variables. A smaller model could be simpler to specify and to update. One of the main findings of the GVAR studies highlighted in Di Mauro and Pesaran (2013) is that for small, open economies one could model only a few countries explicitly in the GVAR to get reliable forecasts. Assenmacher (2013) models only three trading partners together with Switzerland in a GVAR to forecast the Swiss economy. The statement that a small GVAR is sufficient for forecasting makes sense for Switzerland, since trade with the three included trading partners represents a substantial proportion (around 80 per cent) of Switzerland's trade with the countries in the 33-country GVAR. In the case of South Africa, trade with its three main trading partners represents only 55 per cent of trade with countries in the 33-country GVAR. Given the much smaller proportion of trade covered by the three main trading partners of South Africa, it is not clear a priori whether the forecasts of a small GVAR will be as reliable as forecasts of a large GVAR. It therefore justifies further research.

This paper investigates the forecast performance of GVAR models for the South African economy. To our knowledge, this is the first study for South Africa that evaluates the forecast performance of domestic variables with a GVAR model. We also make two contributions to the international literature. First, we compare the forecasting power of the standard 33-country GVAR and a customised small GVAR for South Africa to determine whether the key finding in Di Mauro and Pesaran (2013), as discussed in the previous paragraph, holds for a developing 
country like South Africa. Second, we use the time-varying trade weighted approach, rather than the fixed trade-weighted approach used in previous studies of GVAR forecasting, to account for the large changes in the trade weights of South Africa's trading partners over time.

We compare the forecasts of key South African variables for six different models. The first model is based on a standard 33-country GVAR (Cesa-Bianchi, Pesaran, Rebucci \& Xu, 2012; De Waal \& Van Eyden, forthcoming). The second model is a small GVAR that we customise for South Africa, by only including models for South Africa and the three main trading partners of the country. The third model is a cointegrated VAR model with weakly exogenous foreign variables, known as an augmented VECM or VECX*, for South Africa. It is a simplified version, aligned with the GVAR models, of the VECX* for South Africa developed by De Waal and Van Eyden (2014). The fourth model is a BVAR model containing the same variables as the VECX* model, while the fifth and sixth models are standard benchmark models used for forecast evaluation. These are univariate autoregressive (AR) and random walk (RW) models.

We generate recursive out-of-sample forecasts from one to eight quarters ahead for all the models. A comparison of the root mean squared forecast errors (RMSFEs) of the models shows that the forecast errors of the 33-country GVAR are mostly smaller than the errors of the customised small GVAR for South Africa. The forecasts of both the GVAR models have smaller errors than the VECX* for South Africa over longer forecast horizons. Our findings for South Africa are therefore only partly in line with the findings of Assenmacher (2013) for Switzerland, since the results do show the advantage of a GVAR model for forecasting, but it does not prove that a small GVAR is sufficient. It is not surprising that the forecasts of the large GVAR is better than that of the small GVAR for South Africa as trade with countries included in the small model only represent around 55 per cent of that of trade with trading partners included in the 33-country model. The results emphasise the importance of considering sufficient international trade linkages in macroeconomic modelling. However, and perhaps more importantly, on average, the BVAR model performs the best when it comes to forecasting output, while the AR(1) model outperforms all other models in predicting inflation. Therefore, although it is true that a large GVAR is better suited than a small GVAR in forecasting key variables in South Africa, it is not necessarily true that there are forecasting gains to be derived from using a large GVAR model when compared to small-scale BVAR and benchmark AR models. 
The paper is structured as follows: Section 2 provides a summary of the GVAR forecasting literature, Section 3 includes the methodology of the VECX* and GVAR models, Section 4 comprise the model specifications, Section 5 discusses the forecasting results and Section 6 concludes.

\section{Literature review}

The literature contains ample studies that evaluate the forecast performance of different models for forecasting the South African economy. Models evaluated for forecast accuracy include VAR, VECM, BVAR and Bayesian VECM (BVECM) models (Gupta \& Sichei, 2006; Gupta, 2006; 2007). Gupta and Kabundi (2010; 2011) investigate large-scale Factor Models (FMs) for forecast performance, while Ngoie and Zellner (2012) illustrate the forecasting power of a disaggregated Marshallian macroeconomic model. DSGE models used for forecasting include various closed-economy Dynamic Stochastic General Equilibrium (DSGE) models (Liu \& Gupta, 2007; Liu, Gupta \& Schaling, 2009; 2010), small open economy New Keynesian DSGE models (Steinbach, Mathuloe \& Smit, 2009; Alpanda, Kotzé \& Woglom, 2011), small open economy New Keynesian DSGE-VAR model (Gupta \& Steinbach, 2013) and a recent closedeconomy nonlinear DSGE model (Balcilar, Gupta \& Kotzé, 2013).

Some of these models contain only data for South Africa, while the other models incorporate the rest of the world by using the US as a proxy or by including aggregate fixed trade-weighted foreign variables. The FMs include some global series and variables for selected major trading partners (Germany, the UK and the US). None of these models includes time-varying tradeweighted foreign variables to take into account the major change in the trade shares of South Africa's main trading partners since the mid-1990s.

As far as we know, there is no literature on forecasting domestic variables for South Africa with a GVAR model and for comparing the forecasts with those from VECM or BVAR models augmented with foreign variables, for South Africa. This is the aim of our paper.

The power of GVAR models for forecasting global variables is evident from the literature. In the first GVAR forecasting application, Pesaran, Schuermann and Smith (2009a; 2009b) forecast macroeconomic and financial variables for all 26 regions in the standard 33-country GVAR of DDPS (2007) and DHPS (2007). The paper considers short-term (one quarter in advance) and medium-term (four quarters in advance) out-of-sample forecasts. The results show that double- 
averaged (AveAve) GVAR forecasts, i.e. average forecasts across different GVAR specifications and different estimation windows, generally perform better than benchmark forecasts from univariate autoregressive and random walk models as well as forecasts from individual GVAR models. Smith (2013) summarises the conclusions of Pesaran et al. (2009a) and reinforces the findings by adding out-of-sample data for another four quarters before re-evaluating the models.

In most of the GVAR forecasting literature, the aim is to forecast variables for all countries in the GVAR or for the main countries in the GVAR. Studies often focus on the assessment of 'pooling' methods, such as averaging forecasts over different sample periods, to find the 'pooling' method that performs best in forecasting (Assenmacher-Wesche \& Geissmann, 2013). Eickmeier and $\mathrm{Ng}$ (2011) investigate various weighting structures for the foreign financial variables in the GVAR, for instance the use of inward foreign direct investment weights rather than trade weights, to find the financial weighting scheme with the lowest forecast errors.

The GVAR approach is also a useful tool for nowcasting and for scenario-based forecasting with density forecasts and/or probabilistic forecasts. To nowcast aggregate Euro area GDP growth at a shorter time lag (30 days) than that of the official estimate (45 days), Lui and Mitchell (2013) use a GVAR model with data for all the Euro area countries. Garratt, Lee and Shields (2013) develop a GVAR of actual and expected output for the G7 countries (Canada, France, Germany, Italy, Japan, the UK and the US) that produces reasonable nowcasts of the probability of negative GDP growth in the current period, which could assist policy makers with the early identification of recessions. Greenwood-Nimmo, Nguyen and Shin (2012; 2013) illustrate the effective utilisation of the GVAR approach for scenario-based probabilistic forecasting of macroeconomic variables. Probabilistic forecasts can be determined for single scenarios or for joint scenarios.

In Section 1, we referred to the GVAR forecasting study most relevant to our research, which proves the forecasting power of a small GVAR for Switzerland compared to simpler forecasting models (Assenmacher, 2013). The small Swiss GVAR includes models for Switzerland and three large trading partners: the Euro area, the US and Japan. The Euro area and the US are the two largest trading partners of Switzerland, while Japan is its largest trading partner in Asia. Forecasts of Swiss CPI and GDP from the small GVAR are compared to forecasts from a VECX* model for Switzerland. The study finds that the forecasting performance of the small GVAR is superior to that of the VECX*. 
The three trading partners in the small GVAR for Switzerland account for 80 per cent of Switzerland's average trade between 2007 and 2009 with the countries included in the 33-country GVAR (when compared to an earlier period in the sample, between 2002 and 2004, this figure is 82 per cent). In the case of South Africa, the three main trading partners of South Africa are the Euro area, China and the US. However, since South Africa's trade with the rest of the world is quite diverse, trade with these countries only represents 55 per cent of South Africa's average trade covered by the 33-country GVAR from 2007 to 2009 (55 per cent from 2002 to 2004). As mentioned in Section 1, it is not evident that a small GVAR will be sufficient for South Africa, due to the far lower percentage of trade covered by its three main trading partners compared to the percentage of trade covered by the three trading partners in the small GVAR for Switzerland ${ }^{1}$.

We loosely follow the approach of Assenmacher (2013), which is a summary of the research in Assenmacher-Wesche and Geissmann (2013), but we tailor it for South Africa. An addition in our paper is the comparison of forecasts from both a large GVAR, with 33 countries (26 regions when the Euro area countries are grouped together), and a customised small GVAR for South Africa, with eleven countries (four regions when the Euro area countries are combined). This enables the comparison of forecasts of a large GVAR with those of a small GVAR for South Africa. In addition we compare the forecasting ability of these two models with that of smallscale VECX*, BVAR, and benchmark AR and RW models.

Due to large shifts in the trade weights of South Africa's trading partners over the past two decades, we use the time-varying trade-weighted approach to create the foreign data for estimating and solving the models, rather than the fixed trade-weighted approach followed by Assenmacher (2013). For forecasting, the trade weights are assumed to remain constant at the last available values at the time of the model estimation.

\section{Methodology}

Section 3.1 describes the methodology for building a country-specific VECX* model, such as the South African VECX* developed by De Waal and Van Eyden (2014) and the simpler version

\footnotetext{
${ }^{1}$ We considered the inclusion of more trading partners to represent 80 per cent of South Africa's average trade with the countries included in the 33-country GVAR. However, due to South Africa's diverse trade, we would have had to include at least five more trading partners and the GVAR model would then have included almost half of the countries in the original 33-country ('large') GVAR, thus it would not have been a 'small' model.
} 
adopted in this paper. Section 3.2 discusses the methodology for building GVAR models, like the small and large GVAR models in this study. A GVAR model includes country-specific VECX* models for each of the countries in the global model, thus the GVAR methodology builds on the VECX* methodology. We use the explanation and notation of Di Mauro and Smith (2013).

\subsection{Country-specific VECX* model}

Garratt, Lee, Pesaran and Shin (2006) document the VECX* approach in detail. We provide an overview of the approach.

$\mathrm{A} \operatorname{VARX}^{*}(p, q)$ model is a vector autoregressive $(\operatorname{VAR})$ model with weakly exogenous $(\mathrm{X})$ foreign $\left.{ }^{*}\right)$ variables. The lag orders of the domestic and foreign variables, respectively $p$ and $q$, are selected using the Akaike information criterion (AIC) or the Schwarz Bayesian criterion (SBC). Suppose $p$ and $q$ are both two. The $\operatorname{VARX}^{*}(2,2)$ structure, including a constant and a trend is:

$\mathbf{x}_{t}=\mathbf{a}_{0}+\mathbf{a}_{1} t+\boldsymbol{\Phi}_{1} \mathbf{x}_{t-1}+\boldsymbol{\Phi}_{2} \mathbf{x}_{t-2}+\boldsymbol{\Lambda}_{0} \mathbf{x}_{t}^{*}+\Lambda_{1} \mathbf{x}_{t-1}^{*}+\Lambda_{2} \mathbf{x}_{t-2}^{*}+\mathbf{u}_{t}$

where $t=1,2, \ldots, T$ represents the time periods, $\mathbf{x}_{t}$ is a $k \times 1$ vector of domestic $I(1)$ variables, $\mathbf{x}_{t}^{*}$ is a $k^{*} \times 1$ vector of country-specific foreign $I(1)$ variables and $\mathbf{u}_{t}$ is a process with no serial correlation.

To compute the foreign variables $\left(\mathbf{x}_{t}^{*}\right)$, fixed or time-varying trade weights are used to combine the relevant data of the foreign countries $(j=0,1,2, \ldots, N)$ using the formula

$\mathbf{x}_{t}^{*}=\sum_{j=0}^{N} w_{j} \mathbf{x}_{j t}$,

where $w_{j}$ is the trade share of country $j$ in the trade (average of exports and imports) of the domestic country. The trade share of the domestic country with itself is zero and the trade shares of the foreign countries with the domestic country sum to one (100 per cent).

The domestic variables $\left(\mathbf{x}_{t}\right)$ are endogenous, while the foreign variables $\left(\mathbf{x}_{t}^{*}\right)$ are assumed to be weakly exogenous (long-run forcing for the domestic variables) in the VECX*. This means that 
foreign variables do affect domestic variables in the long term, but the opposite is not true, hence domestic variables cannot affect foreign variables in the long term. This assumption is sensible for small open economies, such as South Africa.

The number of cointegrating relations, known as the rank, of the VARX* in equation (1) is selected based on the trace statistic. A potential VECX* for equation (1) is

$\Delta \mathbf{x}_{t}=\mathbf{c}_{0}-\alpha \beta^{\prime}\left[\mathbf{z}_{t-1}-\gamma(t-1)\right]+\boldsymbol{\Lambda}_{0} \Delta \mathbf{x}_{t}^{*}+\Gamma \Delta \mathbf{z}_{t-1}+\mathbf{u}_{t}$,

with $\mathbf{z}_{t}=\left(\mathbf{x}_{t}^{\prime}, \mathbf{x}_{t}^{\prime *}\right)^{\prime}, \alpha$ a $k \times r$ matrix with the speed of adjustment coefficients and $\beta$ a $\left(k+k^{*}\right) \times r$ matrix with the cointegrating vectors. We can rewrite the $r$ error-correction terms of equation (3) using $\beta=\left(\beta_{x}^{\prime}, \beta_{x *}^{\prime}\right)^{\prime}$ as

$\beta^{\prime}\left(\mathbf{z}_{t}-\gamma t\right)=\beta_{x}^{\prime} \mathbf{x}_{t}+\beta_{x}^{\prime} \mathbf{x}_{t}^{*}-\left(\beta^{\prime} \gamma\right) t$

The long-run multiplier matrix of a normal VECM is $\alpha \beta^{\prime}=\boldsymbol{\Pi}$. However, we know that the foreign variables are assumed weakly exogenous or long-run forcing for the domestic variables. If $\boldsymbol{\Pi}$ is separated as $\boldsymbol{\Pi}^{\prime}=\left(\boldsymbol{\Pi}_{x}^{\prime}, \boldsymbol{\Pi}_{x^{*}}^{\prime}\right)$, the weak exogeneity assumption implies that $\boldsymbol{\Pi}_{x^{*}}=0$. As a result the long-run multiplier matrix of the $\mathrm{VECX}^{*}$ in equation (3) is $\alpha \boldsymbol{\beta}^{\prime}=\boldsymbol{\Pi}_{x}$. This further signifies that the marginal or sub-system VECM for the weakly exogenous foreign variables does not contain the cointegrating vectors of the overall VECX* model since $\boldsymbol{\Pi}_{x^{*}}=0$ (Pesaran, Shin \& Smith, 2000). Equation (5) shows the marginal equations for the foreign variables.

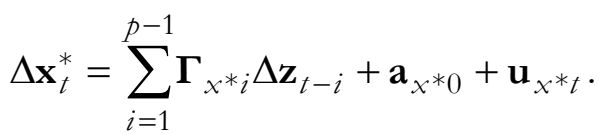

\subsection{GVAR model}

This section contains a brief description of the GVAR model developed by Pesaran, Schuermann and Weiner (2004), Garratt, Lee, Pesaran and Shin (2006), Pesaran and Smith (2006), DDPS (2007) and DHPS (2007). 
In a GVAR system, the domestic and foreign variables are determined endogenously. A GVAR therefore includes country-specific VECX* models for each of the countries $(i=0,1,2, \ldots, N)$ in the global model, with country 0 the reference country. The $N+1$ individual VECX* models are all estimated over the time period $t=1,2, \ldots, T$.

The approach described in Section 3.1 is used to develop each of these county-specific models, with $\mathbf{x}_{i t}$ a $k_{i} \times 1$ vector of endogenous $I(1)$ domestic variables and $\mathbf{x}_{i t}^{*}$ a $k_{i}^{*} \times 1$ vector of weakly exogenous $I(1)$ foreign variables. The number of domestic and foreign variables $\left(k_{i}\right.$ and $\left.k_{i}^{*}\right)$ can differ across countries. Global variables (e.g. the oil price) are endogenous in the model of the dominant country, but weakly exogenous in all the other country models. The dominant or reference country in the GVAR is the US since it dominates global financial markets.

The foreign variables $\left(\mathbf{x}_{i t}^{*}\right)$ for each country $i$ are calculated from the domestic variables of the other countries in the system:

$\mathbf{x}_{i t}^{*}=\sum_{j=0}^{N} w_{i j} \mathbf{x}_{j t}$,

where $w_{i j}$ are fixed or time-varying trade weights that reflect the trade share of country $j$ (with $j$ $=0,1,2, \ldots, N$ ) in the trade (average of exports and imports) of country $i$. The predetermined weights satisfy the conditions $w_{i i}=0$ and $\sum_{j=0}^{N} w_{i j}=1$.

The 'curse of dimensionality' associated with VAR models is avoided due to the weak exogeneity assumption, which allows for the estimation of individual VECX* models for all the countries before solving the GVAR simultaneously to obtain all the endogenous variables $\left(k=\sum_{i=0}^{N} k_{i}\right)$.

To derive the GVAR solution, we write the $\operatorname{VARX}^{*}(2,2)$ from equation (1) as

$$
\mathbf{A}_{i 0} \mathbf{z}_{i t}=\mathbf{a}_{i 0}+\mathbf{a}_{i 1} t+\mathbf{A}_{i 1} \mathbf{z}_{i, t-1}+\mathbf{A}_{i 2} \mathbf{z}_{i, t-2}+\mathbf{u}_{i t},
$$

where $i=0,1,2, \ldots, N$ represent the $N+1$ countries, $\mathbf{z}_{i t}=\left(\mathbf{x}_{i t}^{\prime}, \mathbf{x}_{i t}^{\prime *}\right)^{\prime}, \mathbf{A}_{i 0}=\left(\mathbf{I}_{k i},-\boldsymbol{\Lambda}_{i 0}\right)$, $\mathbf{A}_{i 1}=\left(\boldsymbol{\Phi}_{i 1}, \boldsymbol{\Lambda}_{i 1}\right)$ and $\mathbf{A}_{i 2}=\left(\boldsymbol{\Phi}_{i 2}, \boldsymbol{\Lambda}_{i 2}\right)$. 
Equation (7) is rewritten as

$\mathbf{A}_{i 0} \mathbf{W}_{i} \mathbf{x}_{t}=\mathbf{a}_{i 0}+\mathbf{a}_{i 1} t+\mathbf{A}_{i 1} \mathbf{W}_{i} \mathbf{x}_{t-1}+\mathbf{A}_{i 2} \mathbf{W}_{i} \mathbf{x}_{t-2}+\mathbf{u}_{i t}$,

by means of the identity $\mathbf{z}_{i t}=\mathbf{W}_{i} \mathbf{x}_{t}$, where $\mathbf{x}_{t}=\left(\mathbf{x}_{0 t}^{\prime}, \mathbf{x}_{1 t}^{\prime}, \ldots, \mathbf{x}_{N t}^{\prime}\right)^{\prime}$ is a $k \times 1$ vector of

endogenous variables and $\mathbf{W}_{i}$ is a $\left(k_{i}+k_{i}^{*}\right) \times k$ trade link matrix based on the country-specific trade weights $w_{i j}$.

The individual country models from equation (8) are stacked to get a model of the endogenous variables $\mathbf{x}_{t}$ :

$\mathbf{G}_{0} \mathbf{x}_{t}=\mathbf{a}_{0}+\mathbf{a}_{1} t+\mathbf{G}_{1} \mathbf{x}_{t-1}+\mathbf{G}_{2} \mathbf{x}_{t-2}+\mathbf{u}_{t}$

where $\mathbf{G}_{0}=\left(\begin{array}{c}\mathbf{A}_{00} \mathbf{W}_{0} \\ \mathbf{A}_{10} \mathbf{W}_{1} \\ \vdots \\ \mathbf{A}_{N 0} \mathbf{W}_{N}\end{array}\right), \mathbf{a}_{0}=\left(\begin{array}{c}\mathbf{a}_{00} \\ \mathbf{a}_{10} \\ \vdots \\ \mathbf{a}_{N 0}\end{array}\right), \mathbf{a}_{1}=\left(\begin{array}{c}\mathbf{a}_{01} \\ \mathbf{a}_{11} \\ \vdots \\ \mathbf{a}_{N 1}\end{array}\right), \mathbf{G}_{1}=\left(\begin{array}{c}\mathbf{A}_{01} \mathbf{W}_{0} \\ \mathbf{A}_{11} \mathbf{W}_{1} \\ \vdots \\ \mathbf{A}_{N 1} \mathbf{W}_{N}\end{array}\right), \mathbf{G}_{2}=\left(\begin{array}{c}\mathbf{A}_{02} \mathbf{W}_{0} \\ \mathbf{A}_{12} \mathbf{W}_{1} \\ \vdots \\ \mathbf{A}_{N 2} \mathbf{W}_{N}\end{array}\right)$ and $\mathbf{u}_{t}=\left(\begin{array}{c}\mathbf{u}_{0 t} \\ \mathbf{u}_{1 t} \\ \vdots \\ \mathbf{u}_{N t}\end{array}\right)$

$\mathbf{G}_{0}$ is a known non-singular matrix. As a result, we can premultiply equation (9) by $\mathbf{G}_{0}^{-1}$ to obtain the final GVAR(2) model:

$\mathbf{x}_{t}=\mathbf{b}_{0}+\mathbf{b}_{1} t+\mathbf{F}_{1} \mathbf{x}_{t-1}+\mathbf{F}_{2} \mathbf{x}_{t-2}+\boldsymbol{\varepsilon}_{t}$

where $\mathbf{b}_{0}=\mathbf{G}_{0}^{-1} \mathbf{a}_{0}, \mathbf{b}_{1}=\mathbf{G}_{0}^{-1} \mathbf{a}_{1}, \mathbf{F}_{1}=\mathbf{G}_{0}^{-1} \mathbf{G}_{1}, \mathbf{F}_{2}=\mathbf{G}_{0}^{-1} \mathbf{G}_{2}$ and $\boldsymbol{\varepsilon}_{t}=\mathbf{G}_{0}^{-1} \mathbf{u}_{t}$.

Equation (10) is solved recursively, normally without restrictions on the covariance matrix of the error terms $\left(\boldsymbol{\Sigma}_{\varepsilon}=\mathbf{E}\left(\boldsymbol{\varepsilon}_{t} \boldsymbol{\varepsilon}_{t}^{\prime}\right)\right.$ 


\section{$4 \quad$ Model specifications}

The data for all the models are from the '2009 Vintage' GVAR database of the GVAR Toolbox 1.1 (Smith \& Galesi, 2011), which contains data from 1979Q2 to 2009Q4 for 33 countries that account for around 90 per cent of world output. For clarity, Table 7 in Section A.1 in the appendix provides further information about the definitions, calculations and sources of the data. Detailed information about the data sources and the methods of calculation for the GVAR Toolbox 1.1 database is included in Technical Appendix B of the User Guide compiled by Smith and Galesi (2011).

The country-specific foreign variables for the relevant models are created with three-year moving-average trade-weighted data of the relevant countries.

Data from 1979Q2 to 2004Q4 represent the in-sample period, while the out-of-sample forecast period is from 2005Q1 to 2009Q4. For the in-sample solution, three-year moving-average tradeweights up to 2004 are used. For the out-of-sample recursive forecasts for 2005, the average trade weights between 2002 and 2004 determine the 2005 forecasts. For the recursive estimations, the trade weights are extended when new annual trade weights would have been available. For example, for the out-of-sample recursive forecasts for 2006, the average trade weights between 2003 and 2005 determine the solution, and for the 2009 forecasts, the average trade weights between 2006 and 2008 determine the solution.

\subsection{GVAR models}

We estimate two GVAR models using data from 1979Q1 to 2004Q4. We compare recursive out-of-sample forecasts up to eight quarters ahead with the actual data from 2005Q1 to 2009Q4.

First, we estimate a 33-country GVAR, referred to as the 'large GVAR'. Since the eight Euro area countries from the GVAR database are grouped into a region, it is effectively a 26-region GVAR. The Euro area countries include Austria, Belgium, Finland, France, Germany, Italy, the Netherlands and Spain. We consider the model specification of Cesa-Bianchi et al. (2012), which was also used by De Waal and Van Eyden (forthcoming), but due to the different estimation period (up to 2004Q4 and not 2009Q4); we adjust the specification to find a stable model. 
Second, we estimate a customised small GVAR model for South Africa, to which we refer as the 'small GVAR'. The customised model only includes data for South Africa and its three main trading partners. The highest average trade weights from 2005 to 2009 determine the key trading partners. These trading partners are the Euro area, China and the US. The GVAR thus includes four regions with 11 countries: South Africa, China, the US and the eight Euro area countries.

The foreign variables of the large and small GVARs are not the same. For the countries of each model, the foreign variables are calculated by weighting the foreign data of the countries in the specific GVAR with the relevant three-year moving-average trade shares of those countries. The Weighted-Symmetric augmented Dickey Fuller (WS-ADF) unit root test results show that most of the variables are $I(1)^{2}$. In line with previous GVAR studies, we therefore assume that all the variables are $I(1)$.

Table 1 1 summarises the variables that are included in the country-specific VARX* models of the large (26-region) and small (four-region) GVARs.

Table 1: Variables included in the country-specific VARX* models of the GVARs

\begin{tabular}{lllll}
\hline \multirow{2}{*}{ Variable } & \multicolumn{2}{l}{ All countries excluding US } & US & \\
\cline { 2 - 5 } & Domestic & Foreign & Domestic & Foreign \\
\hline Real GDP & $y_{i t}$ & $y_{i t}^{*}$ & $y_{U S, t}$ & $y_{U S, t}^{*}$ \\
Inflation & $\pi_{i t}$ & $\pi_{i t}^{*}$ & $\pi_{U S, t}$ & $\pi_{U S, t}^{*}, p_{U S, t}^{*}=e_{U S, t}^{*}-p_{U S, t}^{*}$ \\
Real exchange rates & $e p_{i t}=e_{i t}-p_{i t}$ & - & - & $\rho_{U S, t}^{S *}$ \\
Short-term interest rates & $\rho_{i t}^{\mathrm{S}}$ & $\rho_{i t}^{\mathrm{S}}$ & $\rho_{U S, t}^{\mathrm{S}}$ & - \\
Long-term interest rates & $\rho_{i t}^{\mathrm{L}}$ & $\rho_{i t}^{\mathrm{L}}$ & $\rho_{U S, t}^{\mathrm{L}}$ & - \\
\hline Oil price & - & $p_{t}^{\text {oil }}$ & $p_{t}^{\text {oil }}$ & - \\
\hline
\end{tabular}

The domestic variables are real GDP $\left(y_{i t}\right)$, inflation $\left(\pi_{i t}\right)$, real exchange rates $\left(e p_{i t}\right)$, short-term interest rates $\left(\rho_{i t}^{\mathrm{S}}\right)$ and long-term interest rates $\left(\rho_{i t}^{\mathrm{L}}\right)$. Real exchange rates are nominal exchange rates minus domestic prices $\left(e p_{i t}=e_{i t}-p_{i t}\right)^{3}$. The foreign variables that are calculated for each country and for each model are foreign real GDP $\left(y_{i t}^{*}\right)$, foreign inflation $\left(\pi_{i t}^{*}\right)$, foreign shortterm interest rates $\left(\rho_{i t}^{\mathrm{S}}\right)$ and foreign long-term interest rates $\left(\rho_{i t}^{\mathrm{L}^{*}}\right)$. The global variable, the oil

\footnotetext{
2 The results of the WS-ADF test are available from the authors on request.

3 The real exchange rate definition differs from the usual definition of $\left(e-p-p^{*}\right)$. The definition used here is standard to the GVAR literature (for example Pesaran et al., 2004; Pesaran \& Smith, 2006; DDPS (2007); Eickmeier \& Ng, 2011; Cesa-Bianchi et al., 2012; Assenmacher-Wesche \& Geismann, 2013). The definition enables the separation of the domestic (endogenous) variables from the foreign (weakly exogenous) variables, which is important in VECX* and GVAR models.
} 
price $\left(p_{t}^{\text {oil }}\right)$, is added as weakly exogenous in all country VARX* models except for the US VARX* model.

The US specification differs from that of the other countries, since it is the dominant country in the model. The domestic (endogenous) variables for the US are GDP, inflation, short-term interest rates, long-term interest rates and the oil price. The foreign (weakly exogenous) variables for the US are foreign GDP $\left(y_{U S, t}^{*}\right)$, foreign inflation $\left(\pi_{U S, t}^{*}\right)$, foreign exchange rates $\left(e p_{U S, t}^{*}\right)$ and foreign short-term interest rates $\left(\rho_{U S, t}^{S^{*}}\right)$. The foreign long-term interest rate of the US cannot be included, as it is not weakly exogenous in the US VARX* due to the prominence of the US bond market in global financial markets.

Table 2 Table 2 provides the final model specification for the large GVAR, with the domestic lag $\operatorname{order}\left(p_{i}\right)$, the foreign lag order $\left(q_{i}\right)$ and the rank for each of the individual VARX* models.

Table 2: Final country-specific VARX* specifications for large GVAR

\begin{tabular}{llllllll}
\hline Country & $\boldsymbol{p}_{\boldsymbol{i}}$ & $\boldsymbol{q}_{\boldsymbol{i}}$ & Rank & Country & $\boldsymbol{p}_{\boldsymbol{i}}$ & $\boldsymbol{q}_{\boldsymbol{i}}$ & Rank \\
\hline Argentina & 1 & 1 & 1 & New Zealand & 2 & 1 & 1 \\
Australia & 2 & 1 & 2 & Norway & 1 & 1 & 2 \\
Brazil & 2 & 1 & 1 & Peru & 2 & 1 & 1 \\
Canada & 1 & 1 & 1 & Philippines & 2 & 1 & 1 \\
Chile & 2 & 1 & 2 & Saudi Arabia & 2 & 1 & 1 \\
China & 1 & 1 & 1 & Singapore & 1 & 1 & 1 \\
Euro area & 2 & 1 & 1 & South Africa & 2 & 1 & 1 \\
\hline India & 2 & 1 & 1 & Sweden & 1 & 1 & 2 \\
Indonesia & 2 & 1 & 1 & Switzerland & 2 & 1 & 2 \\
Japan & 2 & 1 & 1 & Thailand & 2 & 1 & 1 \\
Korea & 2 & 1 & 1 & Turkey & 2 & 1 & 1 \\
Malaysia & 1 & 1 & 1 & United Kingdom & 2 & 1 & 1 \\
Mexico & 1 & 1 & 2 & United States & 2 & 1 & 1 \\
\hline
\end{tabular}

The AIC determines the number of lags for the domestic variables $\left(p_{i}\right)$ and the number of lags for the foreign variables $\left(q_{i}\right)$ for the individual VARX* models. Maximum lag orders of respectively two and one are considered for $p_{i}$ and $q_{i}$. The rank (i.e. the number of cointegrating vectors) for each of the country models is chosen from the trace statistics (refer to Table Fable-8 in Section A.2 in the appendix).

To determine whether the model is stable, we analyse the persistence profiles and generalised impulse response functions. Persistence profiles (PPs) trace the effects over time of a system shock on all the cointegrating vectors in the GVAR. PPs should converge to zero to indicate a 
return to the long-run equilibrium. If a PP does not converge to zero, the related vector is not a cointegrating vector. We reduce the ranks chosen by the trace statistics for countries with nonconverging persistence profiles. For the final model specification of the large GVAR, the reductions in the number of cointegrating vectors are as follows: from three to one (Canada, Korea and Peru) and from two to one (Indonesia, Japan, New Zealand, Philippines, Saudi Arabia, Singapore, South Africa, Thailand, UK and US). Figure 3 in Section A.4 in the appendix illustrates the PPs for the final specification of the large GVAR.

Generalised impulse response functions (GIRFs) plot the impact over time of a one standard error shock to specific variables on all the variables in the system. If GIRFs do not stabilise over time, there could be misspecification in the GVAR (Smith, 2011). To avoid volatile and unstable GIRFs, we reduce the number of domestic lags for Argentina, Malaysia, Norway and Sweden from two to one. Malaysia initially had no cointegrating vectors in its country model, but after the increase in the number of domestic lags for Malaysia, the rank changed to one.

Weak exogeneity tests on the foreign and global variables in the country-specific VARX* models of the large GVAR support the assumption of weak exogeneity, since the null hypothesis of weak exogeneity is only rejected for three of the 129 variables at a five per cent level of significance. Table 10 in Section A.3 in the appendix contains the results.

The country-specific VECX* models are estimated with an unrestricted trend and a trend restricted to lie in the cointegrating space, whereafter the GVAR is solved for recursive one-step to eight-steps ahead forecasts from 2005Q1 to 2009Q4.

Table 3 Table 3 specifies the domestic lag order $\left(p_{i}\right)$, the foreign lag order $\left(q_{i}\right)$ and the rank for each of the country-specific VARX* models in the small GVAR.

Table 3: Final country-specific VARX* specifications for small GVAR

\begin{tabular}{llll}
\hline Country & $\boldsymbol{p}_{\boldsymbol{i}}$ & $\boldsymbol{q}_{\boldsymbol{i}}$ & Rank \\
\hline China & 2 & 1 & 1 \\
Euro area & 2 & 1 & 1 \\
South Africa & 2 & 1 & 1 \\
United States & 2 & 1 & 1 \\
\hline
\end{tabular}

We use the AIC to determine the number of lags for the domestic $\left(p_{i}\right)$ and foreign $\left(q_{i}\right)$ variables for the country-specific VARX* models, starting with maximum lag orders of respectively two and one. China has a VARX* $(1,1)$ specification according to the AIC, while the Euro area, South 
Africa and the US have $\operatorname{VARX}^{*}(2,1)$ specifications. To reduce serial correlation in the VARX* for China, we adjust its specification to $\operatorname{VARX}^{*}(2,1)$.

Based on the trace statistic results (refer to Table 9 in Section A.2 in the appendix), the model for the Euro area has no cointegrating vectors, the models for China and South Africa have one cointegrating vector each, and the model for the US has three cointegrating vectors. When increasing the rank for the Euro model from zero to one, the PP of the imposed cointegrating vector of the Euro area converges fast. This indicates that the Euro area model does indeed have one cointegrating vector. Since the PP of the US shows non-convergent behaviour with a rank higher than one, we reduce the rank from three to one to avoid misspecification. Figure 4 in Section A.4 in the appendix contains the PPs for the final model specification of the small GVAR.

Weak exogeneity tests are performed on the variables that are assumed to be weakly exogenous in the small GVAR. The results in Table 1Table 11 in Section A.3 in the appendix show that the assumption of weak exogeneity holds for all the relevant variables.

The country-specific VECX* models are estimated with an unrestricted trend and a trend that is restricted to lie within the cointegrating space. The GVAR is then solved recursively to get onestep to eight-steps ahead forecasts from 2005Q1 to 2009Q4.

\subsection{VECX* model}

The VECX* model incorporates quarterly domestic and time-varying trade-weighted foreign data for South Africa from 1979Q2 to 2004Q4. As with the GVAR models, we compare recursive out-of-sample forecasts up to eight quarters ahead with the data from 2005Q1 to 2009Q4.

For consistency, we use the same variables used for the GVARs for the South African VECX* (see Table 1Table 1). We also use the same specification, with one lag for the domestic variables, one lag for the weakly exogenous foreign variables and a rank of one.

The marginal models of the weakly exogenous foreign variables of the VECX* are used to forecast out-of-sample values for the foreign variables. The marginal models are all $\operatorname{VAR}(1)$, that is VAR models of order one. The forecasts for the domestic variables are computed based on the forecasted exogenous variables. 


\subsection{BVAR model}

The vector autoregressive (VAR) model, though 'atheoretical', is particularly useful for forecasting purposes. An unrestricted VAR model, as suggested by Sims (1980), can be written as follows:

$y_{t}=A_{0}+A(L) y_{t}+\varepsilon_{t}$

where $y$ is a $(n \times 1)$ vector of variables being forecasted, which in our case are the same variables used in the country-specific VARX* models of the GVARs; $A(L)$ is a $(n \times n)$ polynomial matrix in the backshift operator $L$ with lag length $p=2$ (as in the VARX*), i.e. $A(L)=$ $A_{1} L+A_{2} L^{2}+\ldots \ldots \ldots \ldots \ldots . . .+A_{p} L^{p} ; A_{0}$ is a $(n \times 1)$ vector of constant terms, and $\varepsilon$ is a $(n \times 1)$ vector of error terms. In our case, we assume that $\varepsilon \sim N\left(0, \sigma^{2} I_{n}\right)$, where $I_{n}$ is a $n \times n$ identity matrix.

Note that the VAR model generally uses equal lag length for all the variables of the model. One drawback of VAR models is that many parameters need to be estimated, some of which may be insignificant. This problem of overparameterization, resulting in multicollinearity and a loss of degrees of freedom, leads to inefficient estimates and possibly large out-of-sample forecasting errors. One solution, often adapted, is simply to exclude the insignificant lags based on statistical tests. Another approach is to use a near VAR, which specifies an unequal number of lags for the different equations.

However, an alternative approach to overcoming this overparameterization, as described in Litterman (1981), Doan, Litterman and Sims (1984), Todd (1984), Litterman (1986), and Spencer (1993), is to use a BVAR model. Instead of eliminating longer lags, the Bayesian method imposes restrictions on these coefficients by assuming that they are more likely to be near zero than the coefficients on shorter lags. However, if there are strong effects from less important variables, the data can override this assumption. The restrictions are imposed by specifying normal prior distributions with zero means and small standard deviations for all coefficients with the standard deviation decreasing as the lags increase. Where the data exhibits non-stationary characteristics, the coefficient on the first own lag of a variable has a mean of unity. This procedure is popularly referred to as the 'Minnesota prior' due to its development at the 
University of Minnesota and the Federal Reserve Bank at Minneapolis, Minnesota.

Formally, as discussed above, the means and variances of the Minnesota prior take the following form:

$\beta_{i} \sim N\left(1, \sigma_{\beta_{i}}^{2}\right)$ and $\beta_{j} \sim N\left(0, \sigma_{\beta_{j}}^{2}\right)$

where $\beta_{i}$ denotes the coefficients associated with the lagged dependent variables in each equation of the VAR, while $\beta_{j}$ represents any other coefficient. In the belief that lagged dependent non-stationary variables are important explanatory variables, the prior means corresponding to them are set to unity, given that, as seen from equation (12), the distribution $a$ priori is centered around a random walk. However, for all the other coefficients, $\beta_{j}$, in a particular equation of the VAR, a prior mean of zero is assigned to suggest that these variables are less important to the model. Note that for the BVAR model, non-stationarity is not an issue, since Sims, Stock and Watson (1990) indicates that the likelihood function has the same Gaussian shape regardless of the presence of non-stationarity. However, following Banbura, Giannone and Reichlin (2010) and Bloor and Matheson (2010), for the variables in the panel that are stationary (namely, the inflation rate, $\pi_{i t}$, and the short-term interest rate, $\rho_{i t}^{\mathrm{S}}$ ), we set a whitenoise prior, i.e. $\bar{\beta}_{i}=0$, otherwise, we impose the random walk prior implying that: $\bar{\beta}_{i}=1$.

The prior variances $\sigma_{\beta_{i}}^{2}$ and $\sigma_{\beta_{j}}^{2}$, specify uncertainty about the prior means $\bar{\beta}_{i}=1$ (or 0 ), and $\bar{\beta}_{j}=0$, respectively. Because of the overparameterization of the VAR, Doan et al. (1984) suggested a formula to generate standard deviations as a function of small numbers of hyperparameters: $w, d$, and a weighting matrix $f(i, j)$. This approach allows the forecaster to specify individual prior variances for a large number of coefficients based on only a few hyperparameters. The specification of the standard deviation of the distribution of the prior imposed on variable $j$ in equation $i$ at lag $m$, for all $i, j$ and $m$, defined as $\sigma_{i, j, m}$, can be specified as follows:

$$
\sigma_{i, j, m}=[w \times g(m) \times f(i, j)] \frac{\hat{\sigma}_{i}}{\hat{\sigma}_{j}}
$$


with $f(i, j)=1$, if $i=j$ and $k_{i j}$ otherwise, with $\left(0 \leq k_{i j} \leq 1\right), g(m)=m^{-d}, d>0$. Note that $\hat{\sigma}_{i}$ is the estimated standard error of the univariate autoregression for variable $i$. The ratio $\hat{\sigma}_{i} / \hat{\sigma}_{j}$ scales the variables to account for differences in the units of measurement. The term $w$ indicates the overall tightness, and is also the standard deviation on the first own lag, with the prior getting tighter as we reduce the value. The parameter $g(m)$ measures the tightness on lag $m$ with respect to lag 1, and is assumed to have a harmonic shape with a decay factor of $d$, which tightens the prior on increasing lags. The parameter $f(i, j)$ represents the tightness of variable $j$ in equation $i$ relative to variable $i$, and by increasing the interaction, i.e. the value of $k_{i j}$, we can loosen the prior. Given that we have domestic as well as world variables within our dataset, where domestic variables would have minimal, if any, effect on world variables, while world variables influence domestic variables, we use a weighting scheme for $k_{i j}$. Following Kinal and Ratner (1986) and Shoesmith (1992), the weight of a world variable in a world equation, as well as a domestic equation, is set at 0.6. The weight of a domestic variable in the other domestic equations is then fixed at 0.1 and its weight in a world equation is set at 0.01 . Finally, the weight of the domestic variable in its own equation is 1.0. These weights are in line with Litterman's circle-star approach, where star (world) variables affect both star and circle (domestic) variables, and circle variables primarily influence only other circle variables. ${ }^{4}$ We follow Banbura et al. (2010), Bloor and Matheson (2010) and De Mol, Giannone and Reichlin (2008) in setting the value of the overall tightness parameter to obtain a desired average fit for the two variables of interest (real GDP and the inflation rate) in the in-sample period (1979:Q2 to 2004:Q4). The optimal value of $w$ (Fit) $(=0.2114)$ obtained in this fashion is then retained for the entire evaluation period. Note that following Banbura et al. (2010) and Bloor and Matheson (2010), the value of $d$ is set equal to 1.0. Specifically, for a desired Fit, $w$ is chosen as follows:

$w(F i t)=\arg \min _{w}\left|F i t-\frac{1}{2} \sum_{i=1}^{2} \frac{M S F E_{i}^{w}}{M S F E_{i}^{0}}\right|$

where $\left.M S F E_{i}^{w}=\frac{1}{T_{0}-p-1} \sum_{t=p}^{T_{0}-2} y_{i, t+1 \mid t}^{w}-y_{i, t+1}\right)^{2}$

Hence, the one-step-ahead mean squared forecast error (MSFE) evaluated using the training sample $t=1, \ldots, T_{0}-1$, with $T_{0}$ being the beginning of the sample period and $p$ being the order of

\footnotetext{
${ }^{4}$ We experimented with higher and lower interaction values, in comparison to those specified above, to the star variables in both the star and circle equations, but the rank ordering of the alternative forecasts remained the same.
} 
the VAR. $M S F E_{t}^{\theta}$ is the MSFE of variable $i$ with the prior restriction imposed exactly $(w=0)$, while the baseline Fit is defined as the average relative MSFE from an OLS-estimated VAR containing the two variables, i.e.:

$$
F i t=\frac{1}{2} \sum_{i=1}^{2} \frac{M S F E_{i}^{\infty}}{M S F E_{i}^{0}}
$$

Finally, once the priors have been specified, the BVAR model is estimated using Theil's (1971) mixed estimation technique. Specifically, suppose we denote a single equation of the VAR model as: $y_{1}=X A+\varepsilon_{1}$, with $\operatorname{Var}\left(\varepsilon_{1}\right)=\sigma^{2} I$, where the matrix $X$ denotes the lagged values of $y_{i, t}$ and the vector $A$ denotes the coefficients $a_{i, j, m}(l)$, with $l$ being the lag operator, on the lagged values of $y_{i, t}$. The stochastic prior restrictions for this single equation can then be written as:

$$
\left[\begin{array}{c}
M_{111} \\
M_{112} \\
\cdot \\
\cdot \\
\cdot \\
M_{n n p}
\end{array}\right]=\left[\begin{array}{cccccc}
\sigma / \sigma_{111} & 0 & \cdot & \cdot & \cdot & 0 \\
0 & \sigma / \sigma_{112} & 0 & \cdot & \cdot & 0 \\
\cdot & \cdot & \cdot & \cdot & \cdot & \cdot \\
\cdot & \cdot & \cdot & \cdot & \cdot & \cdot \\
0 & \cdot & \cdot & \cdot & \cdot & 0 \\
0 & 0 & \cdot & \cdot & 0 & \sigma / \sigma_{n n p}
\end{array}\right]\left[\begin{array}{c}
a_{111} \\
a_{112} \\
\cdot \\
\cdot \\
\cdot \\
a_{n n p}
\end{array}\right]+\left[\begin{array}{c}
u_{111} \\
u_{112} \\
\cdot \\
\cdot \\
\cdot \\
u_{n n p}
\end{array}\right]
$$

Note, $\operatorname{Var}(u)=\sigma^{2} I$ and the prior means $M_{i j m}$ and the prior standard deviation $\sigma_{i j m}$ take the forms shown in equations (12) and (13), with equation (16) written as:

$r=\mathrm{R} A+u$

and the estimates for a typical equation are derived as follows:

$$
\hat{A}=\left(X^{\prime} X+R^{\prime} R\right)^{-1}\left(X^{\prime} y_{1}+R^{\prime} r\right)
$$

Essentially then, the method involves supplementing the data with prior information on the distribution of the coefficients. The number of observations and degrees of freedom are increased by one in an artificial way, for each restriction imposed on the parameter estimates. The loss of degrees of freedom due to over-parameterization associated with a classical VAR model is, therefore, not a concern in the BVAR. Note, we compute point forecasts using the 
posterior mean of the parameters. Specifically, the point estimate of the one-step-ahead forecast is computed as: $\hat{y}_{t+1 \mid t}^{(w, m o)}=\hat{A}_{0}^{(w, m o)}+\hat{A}_{1}^{(w, m o)} y_{t}+\ldots \ldots . .+\hat{A}_{p}^{(w, m o)} y_{t-p+1}$, with the $h$-step ahead forecasts being computed recursively over 2005:Q1-2009:Q4, where $\hat{A}_{i}^{\left(w, d, k_{i j}, m o\right)}, I=0, \ldots, p$ being the posterior mean of the constant and the autoregressive coefficients corresponding to a model $m_{0}$, given the hyperparameters of the models.

\subsection{Univariate AR and random walk models}

Univariate $A R$ and random walk (RW) models are estimated for real GDP and inflation respectively from 1979Q2 to 2004Q4. Recursive out-of sample forecasts are then determined from 2005Q1 to 2009Q4, each time for a forecast horizon (b) up to eight quarters. These simple models are often used in the literature as benchmark models as their forecasts are "surprisingly hard to beat" (Pesaran et al., 2009a; Smith, 2013). The use of an AR(1) model specifically for South Africa has also been stressed recently by Gupta, Kanda, Modise and Paccagnini (forthcoming).

An AR(1) model specification, thus an AR model with a lag order of one, without a trend proves best for both the real GDP and inflation from 1979Q2 to 2004Q4. The AR(1) specifications for real GDP $\left(y_{t}\right)$ and inflation $\left(\pi_{t}\right)$ are

$y_{t}=\alpha_{\mathrm{y}}+\beta_{\mathrm{y}} y_{t-1}+\varepsilon_{t}$ and $\pi_{t}=\alpha_{\pi}+\beta_{\pi} \pi_{t-1}+\varepsilon_{t}$,

while the forecast equations for real GDP $\left(y_{t+b / t}\right)$ and inflation $\left(\pi_{t+b / t}\right)$ are

$y_{t+b / t}=\hat{\alpha}_{\mathrm{y}}+\hat{\beta}_{\mathrm{y}} y_{t+b-1 / t}$ and $\pi_{t+b / t}=\hat{\alpha}_{\pi}+\hat{\beta}_{\pi} \pi_{t+b-1 / t}$.

For the sample period from 1979Q2 to 2004Q4, a RW with a drift fits the real GDP series the best. A RW without a drift fits the inflation series well. The RW model specifications for real GDP and inflation respectively are

$y_{t}=\mu_{\mathrm{y}}+y_{t-1}+\varepsilon_{t}$ and $\pi_{t}=\pi_{t-1}+\varepsilon_{t}$,

while the forecast equations for real GDP and inflation are 
$y_{t+h / t}=h \hat{\mu}_{\mathrm{y}}+y_{t}\left(\right.$ where $\hat{\mu}_{\mathrm{y}}$ is estimated using $\left.\Delta y_{t}=\mu_{\mathrm{y}}+\varepsilon_{t}\right)$ and $\pi_{t+b / t}=\pi_{t}$.

\section{$5 \quad$ Forecast evaluation}

We compare the root mean squared forecast errors (RMSFEs) ${ }^{5}$ and the mean absolute errors (MAEs) of all the models to determine which model provides the best forecasts of two key South African variables: GDP and inflation. The RMSFEs and the MAEs for one-quarter ahead up to eight-quarters ahead are calculated for the recursive out-of-sample forecasts from 2005Q1 to 2009Q4. ${ }^{6}$ The absolute RMSFEs and MAEs in percentage terms are shown for the RW models, while RMSFE and MAE measures for all other models are expressed relative to that of the RW model.

Table 4 compares the RMSFEs and the MAEs for South African GDP at different forecast horizons for the six models. To illustrate the advantage of using the time-varying trade weighted approach over the fixed trade-weighted approach, the measures are provided for both approaches for the large GVAR, small GVAR and VECX* models. The RW model is taken as the benchmark model and RMSFE and MAE measures for all models are expressed relative to this model.

5 The $h$-quarter ahead forecast error for each variable of each model is $e_{t}(b)=y_{t+b}-\hat{y}_{t+b \mid t}$, where $y_{t+b}$ is the
actual value of the variable and $\hat{y}_{t+h \mid t}$ is the forecast of the variable. The $h$-quarter ahead RMSFE is
$\operatorname{RMSFE}(b, \mathrm{R})=100 \sqrt{\mathrm{R}^{-1} \sum_{t=T}^{T+n-1} e_{t}^{2}(b)}$ and the $h$-quarter ahead MAE is $\operatorname{MAE}(h, \mathrm{R})=100 \mathrm{R}^{-1} \sum_{t=T}^{T+n-1}\left|e_{t}(b)\right|$, with $R$ the forecast sample size.

${ }^{6}$ One of the anonymous referees inquired about the possibility of structural breaks. In this regard, it is important to point out the following three issues: (1) Since all models are estimated recursively over the out-of-sample periods: 2005:1-2009:4, the parameter estimates are updated at each recursion and hence, this allows us to account for any structural breaks, for instance due to the global financial crisis, over this period; (2) Also, the GVAR (as well as the other models) accounts for possible structural breaks that might have occurred across various economies over the entire sample, by using time-varying trade-weights, which allows us to capture the change in the relationship amongst the South African variables with the variables from of its trading partners. Possibly, this is the primary reason, one observes that the time-varying GVAR outperforms the fixed-weight-based GVAR consistently; (3) Finally, the CUSUM test conducted on the relationship between the South African GDP and the domestic and foreign variables indicate no breaks for inflation and one for GDP, with the break corresponding exactly with 2005:Q1, from which period we estimate the models recursively in any case. Further, the Bai and Perron (2003) tests of multiple structural breaks conducted on a $\operatorname{VAR}(2)$ involving GDP and inflation- our two variables of concern, also depict no structural breaks. Further details on the test conducted here are available upon request from the authors. 
Table 4: RMSFEs and MAEs for South African GDP

\begin{tabular}{|c|c|c|c|c|c|c|c|c|c|c|}
\hline \multicolumn{11}{|c|}{ RMSFE } \\
\hline \multirow[b]{2}{*}{ Models } & & \multicolumn{8}{|c|}{$\overline{c h}$} & \multirow[b]{2}{*}{ Average } \\
\hline & & 1 & 2 & 3 & 4 & 5 & 6 & 7 & 8 & \\
\hline RW & & 1.0003 & 1.8487 & 2.5941 & 3.2754 & 3.8265 & 4.2368 & 4.6799 & 5.1318 & 3.3242 \\
\hline $\operatorname{AR}(1)$ & & 0.9437 & 0.9893 & 1.0357 & 1.0630 & 1.0630 & 1.0624 & 1.0272 & 1.0069 & 1.0239 \\
\hline \multirow{2}{*}{ Large GVAR } & TV & 0.6945 & 0.7262 & 0.7682 & 0.7706 & 0.7988 & 0.8229 & 0.7898 & 0.8044 & 0.7719 \\
\hline & Fixed & 0.7659 & 0.8376 & 0.9078 & 0.8829 & 0.9339 & 0.9816 & 0.9669 & 0.9819 & 0.9073 \\
\hline \multirow{2}{*}{ Small GVAR } & TV & 0.6938 & 0.7854 & 0.8448 & 0.8405 & 0.8550 & 0.8543 & 0.8118 & 0.8473 & 0.8166 \\
\hline & Fixed & 0.6761 & 0.7706 & 0.8571 & 0.8538 & 0.8976 & 0.9223 & 0.9055 & 0.9257 & 0.8511 \\
\hline \multirow{2}{*}{ VECX* } & TV & 0.6067 & 0.6513 & 0.7169 & 0.7569 & 0.8278 & 0.8686 & 0.8591 & 0.8957 & 0.7729 \\
\hline & Fixed & 0.6194 & 0.6997 & 0.8017 & 0.7614 & 0.8375 & 0.8809 & 0.8700 & 0.8871 & 0.7947 \\
\hline BVAR & & 0.5301 & 0.6093 & 0.7120 & 0.7928 & 0.8534 & 0.8468 & 0.7628 & 0.6704 & 0.7222 \\
\hline
\end{tabular}

MAE

\begin{tabular}{|c|c|c|c|c|c|c|c|c|c|c|}
\hline \multirow[b]{2}{*}{ Models } & & \multicolumn{8}{|c|}{ h } & \multirow[b]{2}{*}{ Average } \\
\hline & & 1 & 2 & 3 & 4 & 5 & 6 & 7 & 8 & \\
\hline RW & & 0.8311 & 1.5939 & 2.3175 & 3.0271 & 3.5958 & 4.0339 & 4.4203 & 4.8045 & 3.0780 \\
\hline $\operatorname{AR}(1)$ & & 0.8017 & 0.7989 & 0.8273 & 0.8593 & 0.8717 & 0.8877 & 0.9026 & 0.9043 & 0.8567 \\
\hline \multirow{2}{*}{ Large GVAR } & TV & 0.6217 & 0.6126 & 0.6333 & 0.6636 & 0.7052 & 0.7272 & 0.7385 & 0.7762 & 0.6848 \\
\hline & Fixed & 0.7069 & 0.8032 & 0.8643 & 0.8601 & 0.9120 & 0.9697 & 0.9497 & 0.9508 & 0.8771 \\
\hline \multirow{2}{*}{ Small GVAR } & TV & 0.6612 & 0.7161 & 0.7554 & 0.7503 & 0.7822 & 0.7970 & 0.7947 & 0.8484 & 0.7632 \\
\hline & Fixed & 0.6617 & 0.7291 & 0.8129 & 0.8244 & 0.8785 & 0.9112 & 0.8968 & 0.9188 & 0.8292 \\
\hline \multirow{2}{*}{ VECX* } & TV & 0.5939 & 0.5813 & 0.6314 & 0.6925 & 0.7635 & 0.8198 & 0.8512 & 0.9007 & 0.7293 \\
\hline & Fixed & 0.6279 & 0.6274 & 0.7166 & 0.6966 & 0.7898 & 0.8381 & 0.8520 & 0.8916 & 0.7550 \\
\hline BVAR & & 0.5251 & 0.5461 & 0.6302 & 0.6964 & 0.7717 & 0.7724 & 0.7120 & 0.6652 & 0.6649 \\
\hline
\end{tabular}

Note: Entries corresponding to the RW model are RMSFEs and MAEs in percentages, while the entries corresponding to the other models are the RMSFE of the specific model relative to the RMSFE of the RW model, or the MAE of the specific model relative to the MAE of the RW model, for a specific horizon (b). 'TV' indicates the time-varying trade weighted approach, while 'Fixed' indicates the fixed trade-weighted approach.

Overall, the BVAR model outperforms all other models, with an average RMSFE and MAE of only 72 per cent and 66 per cent respectively of that of the relevant RW model. The time-varying trade-weighted VECX* and the large time-varying trade-weighted GVAR perform better than the BVAR model at four and five-period forecast horizons, while the large time-varying tradeweighted GVAR performs better than the BVAR model at a six-period forecast horizon. The advantage of using the time-varying trade-weighted approach is clear, since it generally provides better forecasts than the fixed trade-weighted approach for the VECX* and the GVAR models. The forecasts of the large time-varying GVAR are consistently more accurate than that of the small time-varying GVAR, as can be seen from the lower RMSFE and MAE measures for the time-varying trade-weighted GVAR model. On average, the RMSFE and MAE of the large timevarying trade-weighted GVAR model are only 77 per cent and 68 per cent respectively of that of the relevant RW model, while the small time-varying trade-weighted GVAR's RMSFE and MAE 
are equal to 82 per cent and 76 per cent respectively of that of the RW models. Although the time-varying trade-weighted VECX* seems to outperform the large time-varying trade-weighted GVAR model in the first three to four quarters, the large time-varying trade-weighted GVAR provides better forecasts in the subsequent four quarters (five to eight quarters ahead). For the time-varying trade-weighted approach, the forecasts of both the small and large GVARs are better than that of the VECX* in the last three quarters. The simple AR(1) model, which can also be considered a benchmark model for forecasting GDP, is less accurate than the RW model at all horizons three periods and beyond based on the RMSFEs.

Table 5 compares the RMSFEs and MAEs for South African inflation.

Table 5: RMSFEs and MAEs for South African inflation

RMSFE

\begin{tabular}{|c|c|c|c|c|c|c|c|c|c|c|}
\hline \multirow{2}{*}{ Models } & & \multicolumn{8}{|c|}{$\bar{h}$} & \multirow[b]{2}{*}{ Average } \\
\hline & & 1 & 2 & 3 & 4 & 5 & 6 & 7 & 8 & \\
\hline RW & & 0.6348 & 0.7627 & 0.8962 & 1.1065 & 1.1570 & 1.2235 & 1.3588 & 1.2334 & 1.0466 \\
\hline $\operatorname{AR}(1)$ & & 1.0203 & 1.0223 & 0.9663 & 0.8383 & 0.7941 & 0.7170 & 0.6228 & 0.6980 & 0.8349 \\
\hline \multirow{2}{*}{ Large GVAR } & $\mathrm{TV}$ & 1.1500 & 1.0805 & 1.0044 & 0.8280 & 0.8249 & 0.8739 & 0.8745 & 0.9823 & 0.9523 \\
\hline & Fixed & 1.2659 & 1.3279 & 1.2875 & 1.0492 & 1.0748 & 1.1714 & 1.1990 & 1.4290 & 1.2256 \\
\hline \multirow{2}{*}{ Small GVAR } & TV & 1.2108 & 1.1325 & 1.0932 & 0.8861 & 0.8495 & 0.8641 & 0.8272 & 0.8855 & 0.9686 \\
\hline & Fixed & 1.2191 & 1.1158 & 1.0910 & 0.8563 & 0.8580 & 0.9254 & 0.9181 & 1.0458 & 1.0037 \\
\hline \multirow{2}{*}{ VECX* } & TV & 1.1400 & 1.0409 & 1.0091 & 0.8417 & 0.8526 & 0.9237 & 0.9469 & 1.0839 & 0.9799 \\
\hline & Fixed & 1.2437 & 1.1486 & 1.0642 & 0.8159 & 0.8350 & 0.9401 & 0.9776 & 1.1473 & 1.0216 \\
\hline BVAR & & 1.2486 & 1.3086 & 1.2684 & 1.1375 & 1.1848 & 1.2261 & 1.2077 & 1.3950 & 1.2471 \\
\hline \multicolumn{11}{|c|}{ MAE } \\
\hline \multirow{2}{*}{\multicolumn{2}{|c|}{ Models }} & \multicolumn{8}{|c|}{ h } & \multirow[b]{2}{*}{ Average } \\
\hline & & 1 & 2 & 3 & 4 & 5 & 6 & 7 & 8 & \\
\hline RW & & 0.4579 & 0.5859 & 0.6338 & 0.8386 & 0.9660 & 1.0405 & 1.0949 & 0.9652 & 0.8229 \\
\hline $\mathrm{AR}(1)$ & & 1.2714 & 1.1584 & 1.1796 & 0.9728 & 0.8240 & 0.7468 & 0.6884 & 0.7945 & 0.9545 \\
\hline \multirow{2}{*}{ Large GVAR } & TV & 1.2660 & 1.1106 & 1.1826 & 0.9199 & 0.8804 & 0.9014 & 0.9148 & 1.0679 & 1.0305 \\
\hline & Fixed & 1.3618 & 1.4062 & 1.4640 & 1.1391 & 1.1061 & 1.1745 & 1.2240 & 1.4523 & 1.2910 \\
\hline \multirow{2}{*}{ Small GVAR } & $\mathrm{TV}$ & 1.3112 & 1.1741 & 1.2495 & 0.9283 & 0.8678 & 0.8414 & 0.8021 & 0.8720 & 1.0058 \\
\hline & Fixed & 1.3223 & 1.1770 & 1.2158 & 0.8814 & 0.9075 & 0.9371 & 0.9125 & 1.0396 & 1.0491 \\
\hline \multirow{2}{*}{ VECX* } & $\mathrm{TV}$ & 1.1970 & 1.0124 & 1.1296 & 0.9434 & 0.9013 & 0.9241 & 0.9178 & 1.0282 & 1.0067 \\
\hline & Fixed & 1.3389 & 1.1800 & 1.1519 & 0.8785 & 0.8515 & 0.9059 & 0.9334 & 1.1437 & 1.0480 \\
\hline BVAR & & 1.2260 & 1.3053 & 1.4018 & 1.1992 & 1.1741 & 1.2151 & 1.2733 & 1.5283 & 1.2904 \\
\hline
\end{tabular}

Note: See note to Table 4.

The forecasts of the large time-varying trade-weighted GVAR are more accurate than the forecasts of the small trade-weighted GVAR up to a four or five-quarter horizon. Thereafter, the small time-varying trade-weighted GVAR forecasts appear better than that of the large time- 
varying trade-weighted GVAR. The time-varying trade-weighted VECX* provide marginally better forecasts than the time-varying trade-weighted GVAR models in the first two to three quarters, but thereafter the VECX* is outperformed by firstly the large GVAR and then both the large and small GVARs. For forecasts up to three quarters ahead, the benchmark RW and AR(1) models produce more accurate forecasts than the GVAR models, the VECX* and the BVAR model. Thereafter, all the other models, except for the BVAR model, mostly outperform the RW model. From a forecast horizon of four quarters or more, the AR(1) model produces the best forecasts.

Overall, the AR(1) model has the best forecasting ability for South African inflation, followed by the large and the small time-varying trade-weighted GVAR models. The good forecast performance of the $\mathrm{AR}(1)$ is in line with expectations, due to inflation being highly autoregressive in nature. If inflation is the only series to forecast, an $\mathrm{AR}(1)$ model would be better, but if the aim is to forecast additional key macroeconomic variables while accounting for relationships and feedback effects between macroeconomic variables, as in our study, a BVAR, GVAR or VECX* model will be more suitable.

In Table 6, we report the percentage gain (positive entries) or loss (negative entries) obtained from using the large GVAR model (which is the second-best performing model) relative to the BVAR and AR(1) models of GDP and inflation respectively. As can be seen, barring horizons 4, 5 and 6 for output, the GVAR model is always outperformed by the BVAR and AR(1) models. Using the one-sided (upper-tail) MSE-F statistic ${ }^{7}$, developed by McCraken (2007), to determine whether the forecasts generated from an unrestricted model (in our case the large GVAR) is statistically superior to those obtained from a restricted model (BVAR or AR(1)), we find that the GVAR outperforms the BVAR model only at horizon 5 for GDP at the 10 per cent level of significance.

\footnotetext{
7 The MSE-F statistic uses the loss differential, and is given as: $M S E-F=(T-R-h+1)\left(\bar{d} / M S E_{1}\right)$, where $T$ equals the number of observations in the total sample, $R$ equals number of observations used to estimate the model from which we calculate the first forecast (i.e. the in-sample portion of $T$ ), $b$ equals the forecast horizon, $\bar{d}=M \hat{S} E_{0}-M \hat{S} E_{1}, M \hat{S} E_{i}=(T-R-h+1)^{-1} \sum_{t=R}^{T-h}\left(u_{i, t+1}\right)^{2}$ with $i=1,0, M \hat{S} E_{1}$ corresponds to the MSE of the unrestricted model, and $M \hat{S} E_{0}$ corresponds to the MSE of the restricted model.
} 
Table 6: Percentage gain or loss and MSE-F statistic from using the BVAR and AR (1) models relative to the large GVAR

\begin{tabular}{l|llllllll}
\hline & \multicolumn{7}{|c}{$\boldsymbol{h}$} \\
\hline Models & $\mathbf{1}$ & $\mathbf{2}$ & $\mathbf{3}$ & $\mathbf{4}$ & $\mathbf{5}$ & $\mathbf{6}$ & $\mathbf{7}$ & $\mathbf{8}$ \\
\hline $\begin{array}{l}\text { Output: } \\
\text { BVAR with Large GVAR }\end{array}$ & -23.672 & -16.104 & -7.307 & 2.878 & $6.835^{*}$ & 2.917 & -3.414 & -16.654 \\
$\begin{array}{l}\text { Inflation: } \\
\text { AR(1) with Large GVAR }\end{array}$ & -11.277 & -5.387 & -3.788 & 1.235 & -3.737 & -17.951 & -28.784 & -28.945 \\
\hline
\end{tabular}

Note: * indicates significance at 10 per cent level of significance based on the MSE-F statistic.

We conclude this section by performing ex ante out-of-sample forecasts for the period 2009Q4 to 2013Q4, using the best performing models for South African GDP and inflation respectively. Note that in this case, the parameters of the models are no longer estimated recursively, but forecasts are based on the parameter estimates available to the forecaster at 2009Q4 for the BVAR and the AR(1) models. When forecasting GDP, the BVAR model performed best and is used for producing an ex ante forecast for real GDP, while the simple AR(1) model outperformed all other models in terms of forecasting inflation.

The actual and ex ante predicted values for real GDP are shown in Figure 1. It is clear from the graph that the forecasted GDP tracts the actual series fairly well, with exception of 2011Q1, when the predicted value is slightly lower than the actual value for output, and the final six periods, when the model specification is not able to predict the actual slowdown in economic activity.

Figure 1: Actual and forecasted values for South African GDP (2009Q4 - 2013Q4)

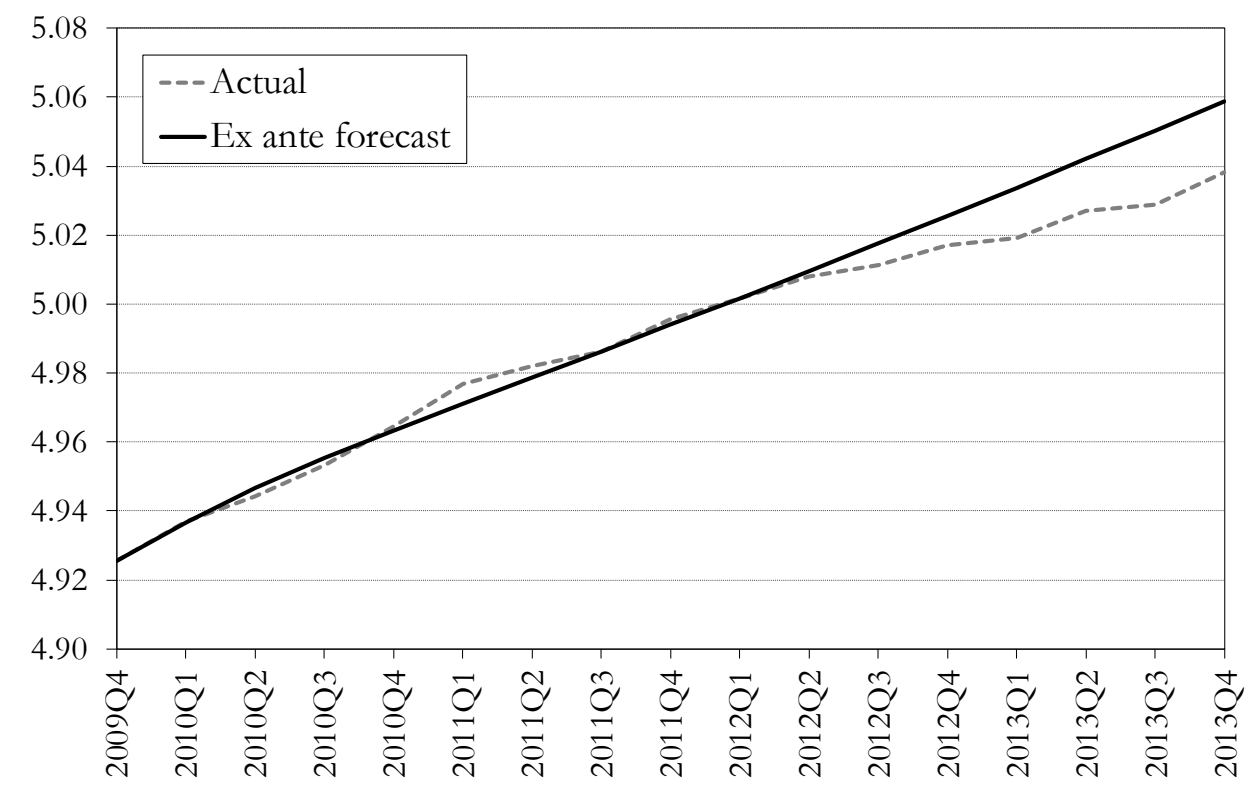


The actual and ex ante predicted values for inflation generated using the $\mathrm{AR}(1)$ specification are depicted in Figure 2. In addition, we also show a one-step ahead forecast over the out-of-sample period, 2009Q1 to 2013Q4. It is evident that accurately forecasting inflation is more difficult than forecasting real GDP. The ex ante forecast is generally able to track actual inflation rates recorded, by picking up the maximum values for the period, while a one-step ahead forecast is better able to pick up upper and lower turning points, albeit with a lag of one quarter.

Figure 2: Actual and forecasted values for South African inflation (2009Q4 - 2013Q4)

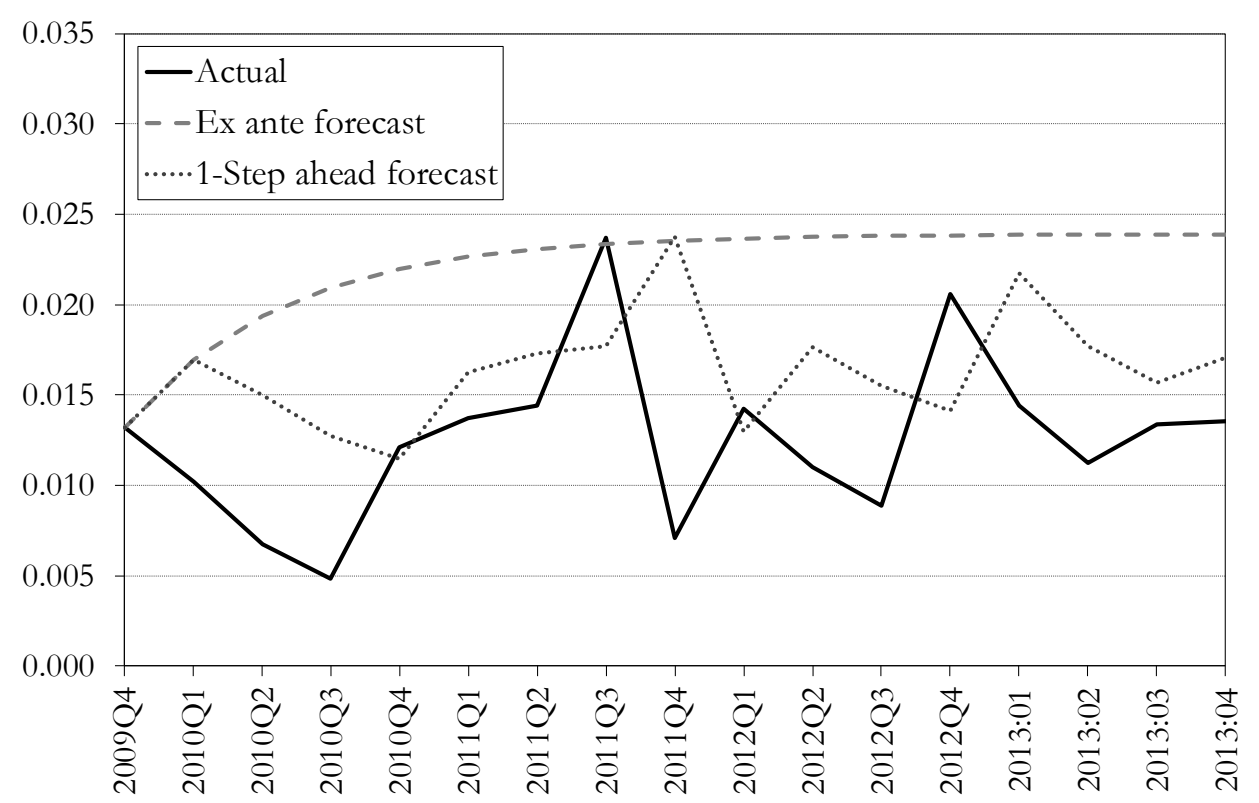

\section{Conclusion}

The forecast errors of the GVAR models are lower than that of the country-specific VECX* for South Africa at longer forecast horizons (more than four quarters ahead). It would therefore be sufficient to develop a simple BVAR or VECX* for South Africa if the aim is to forecast only domestic variables at short forecast horizons. However, if one is interested in global trade linkages and forecasts of variables for specific foreign countries or areas, a VECX* or BVAR model for South Africa would not suffice. Then, a GVAR model that includes many countries and global trade linkages would be more relevant and at least as good, if not better, than a VECX* or BVAR for forecasting domestic variables.

A large (33-country) GVAR generally provides more accurate forecasts of key domestic variables than a customised small (11-country) GVAR for South Africa. This is contrary to one of the findings in Di Mauro and Pesaran (2013) that modelling only a few countries in a GVAR for a 
small, open economy provides reliable forecasts. This is not the case for South Africa - although it is a small open economy - since modelling only a few countries in a customised GVAR for South Africa represents a much smaller percentage of trade with the rest of the world than in the case of a small GVAR for Switzerland (Assenmacher, 2013). The majority of Switzerland's trade is with a few countries, while South African trade is more diverse. The trade shares of the main trading partners of Switzerland have been relatively stable, while the trade shares of South Africa's trading partners have changed markedly since the mid-1990s. By using time-varying trade weights in our model to account for this, it is important to consider all the countries involved in these changes, thereby favouring a large model.

Our study confirms that a large GVAR approach is suitable for forecasting relative to a small GVAR model, and it stresses the importance of incorporating sufficient information on international trade linkages in macroeconomic modelling. However, on average, the BVAR model performs the best when it comes to forecasting output, while the $\operatorname{AR}(1)$ model outperforms all the other models in predicting inflation. So, although it is true that a large GVAR is better suited than a small GVAR in forecasting key variables in South Africa, it is not necessarily true that there are forecasting gains to be derived using a large GVAR model when compared to small-scale BVAR and benchmark AR models. Nevertheless, the role of the GVAR model for carrying out analysis that involves determining the impact of global shocks transmission, especially for a global economy, cannot be ignored, given the richness of the data used in this framework to capture global interrelatedness. Chudik and Pesaran (2014) highlight the usefulness of GVAR modelling in their summary of the many empirical applications of the approach, which includes a reference to a study on the impact of foreign shocks on South Africa by De Waal and Van Eyden (forthcoming). The study shows that shocks to Chinese GDP have a much larger long-term impact on the South African economy in 2009 than in 1995, mainly due to China's trade with South Africa increasing from zero before 1993 to China becoming the largest trading partner of the country in 2009. At the same time, trade with the US decreased substantially and as a result, the effect of shocks to US GDP on South African GDP declined considerably. De Waal and van Eyden (forthcoming) highlights the increased risk to the South African economy should China experience slower GDP growth and they suggest that policy makers monitor the changes in global trade linkages and the resulting changes in the transmission of shocks.

It is important to realize that none of these models is immune to the so-called Lucas (1976) critique. In light of this, future research would be aimed at developing a New-Keynesian GVAR 
DSGE model based on microfoundations, as in Dées, Pesaran, Smith and Smith (2013), and comparing forecast performances with DSGE models (as well as the atheoretical models used in this paper) developed recently for South Africa by Alpanda et al. (2011) and Gupta and Steinbach (2013).

\section{References}

Alpanda, S., Kotzé, K. \& Woglom, G. 2011. Forecasting performance of an estimated DSGE model for the South African economy. South African Journal of Economics, 79(1):50-67.

Assenmacher, K. 2013. Forecasting the Swiss economy with a small GVAR model. In: Di Mauro, F. \& Pesaran, M.H. (eds.) The GVAR handbook: Structure and applications of a macro model of the global economy for policy analysis. Oxford: Oxford University Press.

Assenmacher-Wesche, K. \& Geissmann, D. 2013. Forecasting Swiss inflation and GDP with a small global VAR model. Swiss National Bank: Manuscript.

Bai, J. \& Perron, P. 2003. Computation and analysis of multiple structural change models. Journal of Applied Econometrics, 18(1):1-22.

Balcilar, M., Gupta, R. \& Kotzé, K. 2013. Forecasting South African macroeconomic data with a nonlinear DSGE model. University of Pretoria: Department of Economics, Working Paper 2013-13.

Banbura, M., Giannone, D. \& Reichlin, L. 2010. Large Bayesian VARs. Journal of Applied Econometrics, 25:71-92.

Bloor, C. \& Matheson, T. 2010. Analysing shock transmission in a data-rich environment: A large BVAR for New Zealand. Empirical Economics, 39(2):537-558.

Cesa-Bianchi, A., Pesaran, M.H., Rebucci, A. \& Xu, T. 2012. China's emergence in the world economy and business cycles in Latin America. Economia, Journal of the Latin American and Caribbean Economic Association, 12(2):1-75.

Chudik, A. \& Pesaran, M.H. 2014. Theory and practice of GVAR modeling. University of Southern California, Center for Applied Financial Economics (CAFE), Research Paper 14.04.

Dées, S., Di Mauro, F., Pesaran, M.H. \& Smith, L.V. [DDPS] 2007. Exploring the international linkages of the euro area: A global VAR analysis. Journal of Applied Econometrics, 22:1-38.

Dées, S., Holly, S., Pesaran, M.H. \& Smith, L.V. 2007. [DHPS] Long run macroeconomic relations in the global economy. Economics: The Open-Access, Open-Assessment E-Journal, 1(2007-3). 
Dées, S., Pesaran, M.H., Smith, L.V. \& Smith, R.P. 2013. Constructing multi-country rational expectations models. Oxford Bulletin of Economics and Statistics. DOI: 10.1111/obes.12046.

De Mol, C., Giannone, D. \& Reichlin, L. 2008. Forecasting using a large number of predictors: Is Bayesian regression a valid alternative to principal components? Journal of Econometrics, 146(2):318328.

De Waal, A. \& Van Eyden, R. Forthcoming. The impact of economic shocks in the rest of the world on South Africa: Evidence from a global VAR. Emerging Markets Finance and Trade.

De Waal, A. \& Van Eyden, R. 2014. Monetary policy and inflation in South Africa: A VECM augmented with foreign variables. South African Journal of Economics, 82(1):117-140.

Di Mauro, F. \& Pesaran, M.H. 2013. Introduction: An overview of the GVAR approach and the handbook. In: Di Mauro, F. \& Pesaran, M.H. (eds.) The GVAR handbook: Structure and applications of a macro model of the global economy for policy analysis. Oxford: Oxford University Press.

Di Mauro, F. \& Smith, L.V. 2013. The basic GVAR DdPS model. In: Di Mauro, F. \& Pesaran, M.H. (eds.) The GVAR handbook: Structure and applications of a macro model of the global economy for policy analysis. Oxford: Oxford University Press.

Doan, T.A., Litterman, R.B. \& Sims, C.A. 1984. Forecasting and conditional projection using realistic prior distributions. Econometric Reviews, 3:1-100.

Eickmeier, S. \& Ng, T. 2011. How do credit supply shocks propogate internationally? A GV AR approach. CEPR: Discussion paper 8720.

Garratt, A., Lee, K., Pesaran, M.H. \& Shin, Y. 2006. Global and national macroeconometric modelling: A long-run structural approach. Oxford: Oxford University Press.

Garratt, A., Lee, K. \& Shields, K. 2013. Global recessions and output interdependencies in a GVAR model of actual and expected output in the G7. In: Di Mauro, F. \& Pesaran, M.H. (eds.) The GVAR handbook: Structure and applications of a macro model of the global economy for policy analysis. Oxford: Oxford University Press.

Greenwood-Nimmo, M.J., Nguyen, V.H. \& Shin, Y. 2012. Probabilistic forecasting of output growth, inflation and the balance of trade in a GVAR framework. Journal of Applied Econometrics, 27:554-573.

Greenwood-Nimmo, M., Nguyen, V.H. \& Shin, Y. 2013. Using global VAR models for scenariobased forecasting and policy analysis. In: Di Mauro, F. \& Pesaran, M.H. (eds.) The GVAR handbook: Structure and applications of a macro model of the global economy for policy analysis. Oxford: Oxford University Press. 
Gupta, R. 2006. Forecasting the South African economy with VARs and VECMs. South African Journal of Economics, 74(4):611-628.

Gupta, R. 2007. Forecasting the South African economy with Gibbs sampled BVECMs. South African Journal of Economics, 75(4):631-643.

Gupta, R. \& Kabundi, A. 2010. Forecasting macroeconomic variables in a small open economy: A comparison between small- and large-scale models. Journal of Forecasting, 29:168-185.

Gupta, R. \& Kabundi, A. 2011. A large factor model for forecasting macroeconomic variables in South Africa. International Journal of Forecasting, 27:1076-1088.

Gupta, R., Kanda, P.T., Modise M.P. \& Paccagnini, A. Forthcoming. DSGE model-based forecasting of modeled and non-modeled inflation variables in South Africa. Applied Financial Economics.

Gupta, R. \& Sichei, M.M. 2006. A BVAR model for the South African economy. South African Journal of Economics, 74(3):391-409.

Gupta, R. \& Steinbach, R. 2013. A DSGE-VAR model for forecasting key South African macroeconomic variables. Economic Modelling, 33:19-33.

Kinal, T. \& Ratner, J. 1986. A VAR forecasting model of a regional economy: Its construction and comparison. International Regional Science Review, 10(2):113-126.

Litterman, R.B. 1981. A Bayesian procedure for forecasting with vector autoregressions. Federal Reserve Bank of Minneapolis, Working Paper.

Litterman, R.B. 1986. Forecasting with Bayesian vector autoregressions - Five years' experience. Journal of Business and Economic Statistics, 4:25-38.

Liu, G. \& Gupta, R. 2007. A small-scale DSGE model for forecasting the South African economy. South African Journal of Economics, 75(2):179-193.

Liu, G., Gupta, R. \& Schaling, E. 2009. A New-Keynesian DSGE model for forecasting the South African economy. Journal of Forecasting, 28:387-404.

Liu, G., Gupta, R. \& Schaling, E. 2010. Forecasting the South African economy: a hybrid-DSGE approach. Journal of Economic Studies, 37(2):181-195.

Lucas, R.E. Jr. 1976. Econometric policy evaluation: a critique. Carnegie Rochester Conference Series on Public Policy, 1:19-46. 
Lui, S. \& Mitchell, J. 2013. Nowcasting quarterly euro-area GDP growth using a global VAR model. In: Di Mauro, F. \& Pesaran, M.H. (eds.) The GVAR bandbook: Structure and applications of a macro model of the global economy for policy analysis. Oxford: Oxford University Press.

McCracken, M.W. 2007. Asymptotics for out-of-sample tests of Granger causality. Journal of Econometrics 140:719-752.

Ngoie, J.K. \& Zellner, A. 2012. The use of a Marshallian macroeconomic model for policy evaluation: Case of South Africa. Macroeconomic Dynamics, 16:423-448.

Pesaran, M.H., Schuermann, T. \& Smith, L.V. 2009a. Forecasting economic and financial variables with Global VARs. International Journal of Forecasting, 25:642-675.

Pesaran, M.H., Schuermann, T. \& Smith, L.V. 2009b. Rejoinder to comments on forecasting economic and financial variables with Global VARs. International Journal of Forecasting, 25:703-715.

Pesaran, M.H., Schuermann, T. \& Weiner, S. 2004. Modelling regional interdependencies using a global error-correcting macroeconometric model. Journal of Business and Economic Statistics, 22(2):129-162.

Pesaran, M.H., Shin, Y. \& Smith, R.J. 2000. Structural analysis of vector error correction models with exogenous I(1) variables. Journal of Econometrics, 97(2):293-343.

Pesaran, M.H. \& Smith, R. 2006. Macroeconometric modelling with a global perspective. The Manchester School, 74(Supplement 1):24-49.

Shoesmith, G.L. 1992. Co-integration, error correction and medium-term regional VAR forecasting. Journal of Forecasting, 11(1):91-109.

Sims, C.A. 1980. Macroeconomics and reality. Econometrica, 48(1):1-48.

Sims, C.A., Stock, J.H. \& Watson, M.W. 1990. Inference in linear time series models with some unit roots. Econometrica, 58:113-144.

Smith, L.V. 2011. A course on global VAR modelling. Course presented at the EcoMod Modeling School in Brussels, Belgium from 11-13 July.

Smith, L.V. 2013. Short- and medium-term forecasting using 'pooling' techniques. In: Di Mauro, F. \& Pesaran, M.H. (eds.) The GVAR handbook: Structure and applications of a macro model of the global economy for policy analysis. Oxford: Oxford University Press.

Smith, L.V. \& Galesi, A. 2011. GVAR Toolbox 1.1. [Online] Available from: http:// www.cfap.jbs.cam.ac.uk/research/gvartoolbox [Accessed: 2011-08-09].

Spencer, D.E. 1993. Developing a Bayesian vector autoregression forecasting model. International 
Journal of Forecasting, 9:407-421.

Steinbach, M.R., Mathuloe, P.T. \& Smit, B.W. 2009. An open economy New Keynesian DSGE model of the South African economy. South African Journal of Economics, 77(2):207-227.

Theil, H. 1971. Principles of Econometrics. John Wiley and Sons, New York, and North-Holland Publishing Company, Amsterdam.

Todd, R.M. 1984. Improving economic forecasting with Bayesian vector autoregression. Quarterly Review, Federal Reserve Bank of Minneapolis, Fall:18-29. 


\section{Appendix}

\section{A.1 Data definitions and sources}

Table 7 provides the definitions, calculations and data sources for the variables in Table 1.

Table 7: Variable definitions, calculations and data sources

\begin{tabular}{|c|c|c|c|}
\hline Variable & Definition & Calculation & Data source \\
\hline$y$ & $\begin{array}{l}\text { Real GDP of South Africa } \\
\text { (Constant } 2000 \text { prices) }\end{array}$ & $\ln ($ real GDP) & $\begin{array}{l}\text { Real GDP: } \\
\text { IFS 99BVRZF } \ddagger\end{array}$ \\
\hline$\pi$ & $\begin{array}{l}\text { Inflation rate of South } \\
\text { Africa (Quarterly \%) }\end{array}$ & $\Delta(\ln (p))$ & Calculated \\
\hline$e$ & $\begin{array}{l}\text { Nominal effective exchange } \\
\text { rate of South Africa (Time- } \\
\text { varying trade-weighted } \\
\text { Rand per foreign currency) }\end{array}$ & $\begin{array}{l}\ln \text { (nominal effective exchange } \\
\text { rate) [Nominal effective } \\
\text { exchange rate = time-varying } \\
\text { trade-weighted exchange rate } \\
\text { of South Africa] }\end{array}$ & $\begin{array}{l}\text { Bilateral exchange rates } \\
\text { (units of foreign currency } \\
\text { per US Dollar): } \\
\text { Bloomberg } \ddagger\end{array}$ \\
\hline$p$ & CPI of South Africa & $\ln (\mathrm{CPI})$ & $\begin{array}{l}\text { CPI: } \\
\text { IFS 64ZF } \ddagger \\
\text { (Seasonally adjust the series) }\end{array}$ \\
\hline$e p$ & $\begin{array}{l}\text { Real effective exchange rate } \\
\text { of South Africa }\end{array}$ & $\begin{array}{l}\ln \text { (real effective exchange rate) } \\
=e-p\end{array}$ & Calculated \\
\hline$\rho^{s}$ & $\begin{array}{l}\text { Short-term interest rate of } \\
\text { South Africa (Quarterly \%) }\end{array}$ & $\begin{array}{l}0.25 * \ln (1+\text { short-term interest } \\
\text { rate } / 100)\end{array}$ & $\begin{array}{l}\text { Short-term interest rate } \\
\text { (Treasury bill rate): } \\
\text { IFS 60CZF } \ddagger\end{array}$ \\
\hline$\rho^{L}$ & $\begin{array}{l}\text { Long-term interest rate of } \\
\text { South Africa (Quarterly \%) }\end{array}$ & $\begin{array}{l}0.25^{*} \ln (1+\text { long-term interest } \\
\text { rate } / 100)\end{array}$ & $\begin{array}{l}\text { Long-term interest rate } \\
\text { (government bond yield): } \\
\text { IFS 61ZF } \neq\end{array}$ \\
\hline$y^{*}$ & $\begin{array}{l}\text { Time-varying trade- } \\
\text { weighted foreign real GDP } \\
\text { (Index: } 2000=100 \text { ) }\end{array}$ & $\ln ($ foreign real GDP) & $\begin{array}{l}\text { Real GDP for each of the } \\
32 \text { other countries: } \\
\text { Source depends on country } \ddagger\end{array}$ \\
\hline$\pi^{*}$ & $\begin{array}{l}\text { Time-varying trade- } \\
\text { weighted foreign inflation } \\
\text { rate (Quarterly \%) }\end{array}$ & $\Delta\left(\ln \left(p^{*}\right)\right)$ & Calculated \\
\hline$p^{*}$ & $\begin{array}{l}\text { Time-varying trade- } \\
\text { weighted foreign CPI } \\
\text { (Index: } 2000=100 \text { ) }\end{array}$ & $\ln ($ foreign $\mathrm{CPI})$ & $\begin{array}{l}\text { CPI for each of the } 32 \\
\text { other countries: } \\
\text { Source depends on country }\end{array}$ \\
\hline$\rho^{\varsigma^{*}}$ & $\begin{array}{l}\text { Time-varying trade- } \\
\text { weighted foreign short- } \\
\text { term interest rate } \\
(\text { Quarterly \%) }\end{array}$ & $\begin{array}{l}0.25 * \ln (1+\text { foreign short-term } \\
\text { interest rate } / 100))\end{array}$ & $\begin{array}{l}\text { Short-term interest rate for } \\
\text { each of the } 32 \text { countries: } \\
\text { Source depends on country } \ddagger\end{array}$ \\
\hline$\rho^{L^{*}}$ & $\begin{array}{l}\text { Time-varying trade- } \\
\text { weighted foreign long-term } \\
\text { interest rate (Quarterly \%) }\end{array}$ & $\begin{array}{l}0.25^{*} \ln (1+\text { foreign long-term } \\
\text { interest rate } / 100))\end{array}$ & $\begin{array}{l}\text { Long-term interest rate for } \\
\text { each of the } 32 \text { countries: } \\
\text { Source depends on country }\end{array}$ \\
\hline$p^{o i l}$ & $\begin{array}{l}\text { Oil price } \\
\text { (US Dollar) }\end{array}$ & $\ln$ (oil price) & $\begin{array}{l}\text { Oil price (Brent): } \\
\text { Bloomberg } \\
\text { Ticker: CO1 Comdty } \ddagger\end{array}$ \\
\hline
\end{tabular}

¥ The data are from the GVAR Toolbox 1.1 dataset (Smith \& Galesi, 2011), known as the '2009 vintage'. 


\section{A.2 Ranks of the country-specific VARX* models}

Table 8 and Table 9 contain the trace statistics for determining the number of cointegrating relations for the countries in the large GVAR and for those in the small GVAR. The trace statistics in bold font indicate the rank chosen for each country. These are determined by finding the first statistic for each country where the null hypothesis $($ rank $=r)$ cannot be rejected.

Table 8: Trace statistics at different rank orders for cointegration testing for large GVAR

\begin{tabular}{|c|c|c|c|c|c|c|c|}
\hline Statistic & Argentina & Australia & Brazil & Canada & Chile & China & Euro area \\
\hline \# Domestic & 4 & 5 & 4 & 5 & 4 & 4 & 5 \\
\hline \# Foreign & 5 & 5 & 5 & 5 & 5 & 5 & 5 \\
\hline$r=0$ & $132.54 \dagger$ & $163.83 \dagger$ & $139.51 \dagger$ & $219.24 \dagger$ & $182.96 \dagger$ & $133.31 \dagger$ & $155.60 \dagger$ \\
\hline$r=1$ & 67.10 & $113.04 \dagger$ & 64.61 & $133.06 \dagger$ & $94.65+$ & 76.75 & 99.57 \\
\hline$r=2$ & 31.90 & 63.84 & 26.46 & $85.28+$ & 39.53 & 42.61 & 54.35 \\
\hline$r=3$ & 6.83 & 39.51 & 10.03 & 43.24 & 9.25 & 17.03 & 28.86 \\
\hline$r=4$ & & 16.59 & & 12.90 & & & 7.75 \\
\hline Statistic & India & Indonesia & Japan & Korea & Malaysia & Mexico & $\begin{array}{l}\text { New } \\
\text { Zealand }\end{array}$ \\
\hline \# Domestic & 4 & 4 & 5 & 5 & 4 & 4 & 5 \\
\hline \# Foreign & 5 & 5 & 5 & 5 & 5 & 5 & 5 \\
\hline$r=0$ & $129.91 \dagger$ & $149.04 \dagger$ & $205.63 \dagger$ & $242.40+$ & 100.73 & $168.57 \dagger$ & $197.06 \dagger$ \\
\hline$r=1$ & 76.35 & $82.99 \dagger$ & $127.37 \dagger$ & $164.08 \dagger$ & 61.11 & $81.61 \dagger$ & $122.03 \dagger$ \\
\hline$r=2$ & 43.22 & 37.68 & 73.31 & $93.85 \dagger$ & 26.41 & 45.09 & 73.31 \\
\hline$r=3$ & 15.68 & 16.14 & 41.84 & 41.64 & 8.18 & 18.27 & 39.26 \\
\hline$r=4$ & & & 14.29 & 12.44 & & & 15.61 \\
\hline Statistic & Norway & Peru & Philippines & $\begin{array}{l}\text { Saudi } \\
\text { Arabia }\end{array}$ & Singapore & $\begin{array}{l}\text { South } \\
\text { Africa }\end{array}$ & Sweden \\
\hline \# Domestic & 5 & 4 & 4 & 3 & 4 & 5 & 5 \\
\hline \# Foreign & 5 & 5 & 5 & 5 & 5 & 5 & 5 \\
\hline$r=0$ & $173.49 \dagger$ & $170.29 \dagger$ & $160.97 \dagger$ & $120.99 \dagger$ & $161.07 \dagger$ & $172.57 \dagger$ & $173.03 \dagger$ \\
\hline$r=1$ & $113.28 \dagger$ & $106.52 \dagger$ & $81.81 \dagger$ & $58.44 \dagger$ & $83.97 \dagger$ & $111.90 \dagger$ & $117.16 \dagger$ \\
\hline$r=2$ & 61.89 & $54.24 \dagger$ & 23.72 & 24.86 & 45.06 & 61.91 & 66.91 \\
\hline$r=3$ & 25.48 & 16.10 & 8.03 & & 15.56 & 29.32 & 29.71 \\
\hline$r=4$ & 5.95 & & & & & 8.39 & 9.89 \\
\hline Statistic & Switzerland & Thailand & Turkey & $\begin{array}{l}\text { United } \\
\text { Kingdom }\end{array}$ & $\begin{array}{l}\text { United } \\
\text { States }\end{array}$ & & \\
\hline \# Domestic & 5 & 4 & 4 & 5 & 5 & & \\
\hline \# Foreign & 5 & 5 & 5 & 5 & 4 & & \\
\hline$r=0$ & $195.91 \dagger$ & $165.66 \dagger$ & $113.40 \dagger$ & $209.72 \dagger$ & $209.42 \dagger$ & & \\
\hline$r=1$ & $115.98 \dagger$ & $97.30 \dagger$ & 66.68 & $114.55 \dagger$ & $119.05 \dagger$ & & \\
\hline$r=2$ & 61.18 & 49.88 & 34.07 & 68.10 & 65.51 & & \\
\hline$r=3$ & 32.52 & 12.95 & 10.65 & 36.76 & 39.14 & & \\
\hline$r=4$ & 9.82 & & & 11.23 & 16.20 & & \\
\hline
\end{tabular}

† Null hypothesis rejected at the 5 per cent level of statistical significance. 
Table 9: Trace statistics at different rank orders for cointegration testing for small GVAR

\begin{tabular}{lllll}
\hline Statistic & China & Euro area & South Africa & United States \\
\hline \# Domestic & 4 & 5 & 5 & 5 \\
\# Foreign & 5 & 5 & 5 & 5 \\
$r=0$ & $129.76 \dagger$ & $\mathbf{1 3 4 . 9 5}$ & $169.18 \dagger$ & $224.63 \dagger$ \\
$r=1$ & $\mathbf{7 6 . 5 9}$ & 84.06 & $\mathbf{1 0 8 . 4 9}$ & $130.39 \dagger$ \\
$r=2$ & 34.95 & 52.63 & 55.94 & $85.72 \dagger$ \\
$r=3$ & 13.46 & 28.52 & 28.11 & $\mathbf{4 7 . 8 5}$ \\
$r=4$ & & 10.29 & 5.50 & 20.20 \\
\hline
\end{tabular}

$\dagger$ Null hypothesis rejected at the 5 per cent level of statistical significance.

\section{A.3 Weak exogeneity tests}

Table 10 displays the F-statistics of the weak exogeneity test for the foreign and global variables in the large GVAR. The weak exogeneity assumption is only rejected for three of the 129 variables.

Table 10: Weak exogeneity test statistics for large GVAR

\begin{tabular}{|c|c|c|c|c|c|c|c|}
\hline Country & $F$-test & $y^{*}$ & $\pi^{*}$ & $e p^{*}$ & $\rho^{\mathrm{S*}}$ & $\rho^{\mathrm{L}^{*}}$ & $p^{\text {oil }}$ \\
\hline Argentina & $\mathrm{F}(1,84)$ & 0.18 & 0.19 & & 0.00 & 0.43 & 0.14 \\
\hline Australia & $\mathrm{F}(2,77)$ & 0.05 & 1.57 & & 0.86 & 0.35 & 0.15 \\
\hline Brazil & $\mathrm{F}(1,80)$ & 0.44 & 0.62 & & 0.17 & 0.00 & 0.78 \\
\hline Canada & $\mathrm{F}(1,83)$ & 0.73 & 0.02 & & 2.57 & 0.07 & 0.02 \\
\hline Chile & $\mathrm{F}(2,79)$ & 1.62 & 0.13 & & 0.18 & 0.35 & 1.46 \\
\hline China & $\mathrm{F}(1,84)$ & 0.11 & 0.41 & & 0.80 & $6.03+$ & 0.86 \\
\hline Euro area & $\mathrm{F}(1,78)$ & 0.67 & 0.26 & & 1.04 & 0.27 & 0.10 \\
\hline India & $\mathrm{F}(1,80)$ & 0.28 & 0.29 & & 0.10 & 0.46 & 0.32 \\
\hline Indonesia & $\mathrm{F}(1,80)$ & 0.10 & 1.28 & & 0.01 & 2.52 & 0.28 \\
\hline Japan & $\mathrm{F}(1,78)$ & 1.54 & 0.19 & & 0.60 & 2.41 & 3.25 \\
\hline Korea & $\mathrm{F}(1,78)$ & $5.62 \dagger$ & 0.76 & & 0.95 & 0.03 & 0.87 \\
\hline Malaysia & $\mathrm{F}(1,84)$ & 0.78 & 0.20 & & 0.40 & 0.67 & 0.00 \\
\hline Mexico & $\mathrm{F}(2,83)$ & $3.12 \dagger$ & 0.79 & & 0.35 & 1.14 & 0.08 \\
\hline New Zealand & $\mathrm{F}(1,78)$ & 1.69 & 0.05 & & 0.12 & 0.17 & 3.53 \\
\hline Norway & $\mathrm{F}(2,82)$ & 0.84 & 1.60 & & 0.46 & 0.51 & 2.32 \\
\hline Peru & $\mathrm{F}(1,80)$ & 1.87 & 2.14 & & 0.85 & 0.12 & 2.10 \\
\hline Philippines & $\mathrm{F}(1,80)$ & 0.82 & 0.60 & & 0.00 & 0.13 & 3.37 \\
\hline Saudi Arabia & $\mathrm{F}(1,82)$ & 0.01 & 0.02 & & 0.75 & 0.04 & 0.01 \\
\hline Singapore & $\mathrm{F}(1,84)$ & 0.40 & 3.25 & & 0.03 & 0.29 & 0.03 \\
\hline South Africa & $\mathrm{F}(1,78)$ & 0.13 & 0.21 & & 0.44 & 0.57 & 0.04 \\
\hline Sweden & $\mathrm{F}(2,82)$ & 0.53 & 0.93 & & 0.55 & 0.05 & 0.80 \\
\hline Switzerland & $\mathrm{F}(2,77)$ & 0.61 & 0.31 & & 0.02 & 0.11 & 0.41 \\
\hline Thailand & $\mathrm{F}(1,80)$ & 1.77 & 0.45 & & 0.01 & 1.41 & 0.25 \\
\hline Turkey & $\mathrm{F}(1,80)$ & 0.19 & 0.88 & & 0.21 & 0.69 & 0.13 \\
\hline United Kingdom & $\mathrm{F}(1,78)$ & 3.03 & 2.47 & & 0.42 & 0.19 & 1.98 \\
\hline United States & $\mathrm{F}(1,80)$ & 0.14 & 0.17 & 0.45 & 2.41 & & \\
\hline
\end{tabular}

$\uparrow$ Null hypothesis of weak exogeneity rejected at the 5 per cent level of statistical significance. 
The weak exogeneity test results for the small GVAR are in Table 11 Table 1. The null hypothesis of weak exogeneity is not rejected for any of the foreign or global variables.

Table 11: Weak exogeneity test statistics for small GVAR

\begin{tabular}{llllllll}
\hline Country & $F$-test & $y^{*}$ & $\pi^{*}$ & $e p^{*}$ & $\rho^{\mathrm{S}^{*}}$ & $\rho^{\mathrm{L}^{*}}$ & $p^{\text {oil }}$ \\
\hline China & $\mathrm{F}(1,80)$ & 0.39 & 0.24 & & 0.52 & 0.65 & 0.23 \\
Euro area & $\mathrm{F}(1,78)$ & 0.01 & 0.36 & & 1.86 & 0.32 & 0.11 \\
South Africa & $\mathrm{F}(1,78)$ & 0.49 & 1.23 & & 0.19 & 0.54 & 0.01 \\
United States & $\mathrm{F}(1,80)$ & 0.73 & 1.09 & 1.55 & 0.01 & & \\
\hline
\end{tabular}

$\dagger$ Null hypothesis of weak exogeneity rejected at the 5 per cent level of statistical significance.

\section{A.4 Persistence profiles}

Figure 3 shows the persistence profiles (PPs) of a selection of cointegrating vectors of South Africa and its key trading partners from the large GVAR. The PPs of the other cointegrating vectors in the large GVAR (not shown here) also converge to zero at a fast rate, indicating that the system will return to the long-run equilibrium following a shock to all the cointegrating vectors.

Figure 3: Persistence profiles of cointegrating vectors of South Africa's key trading partners in the large GVAR

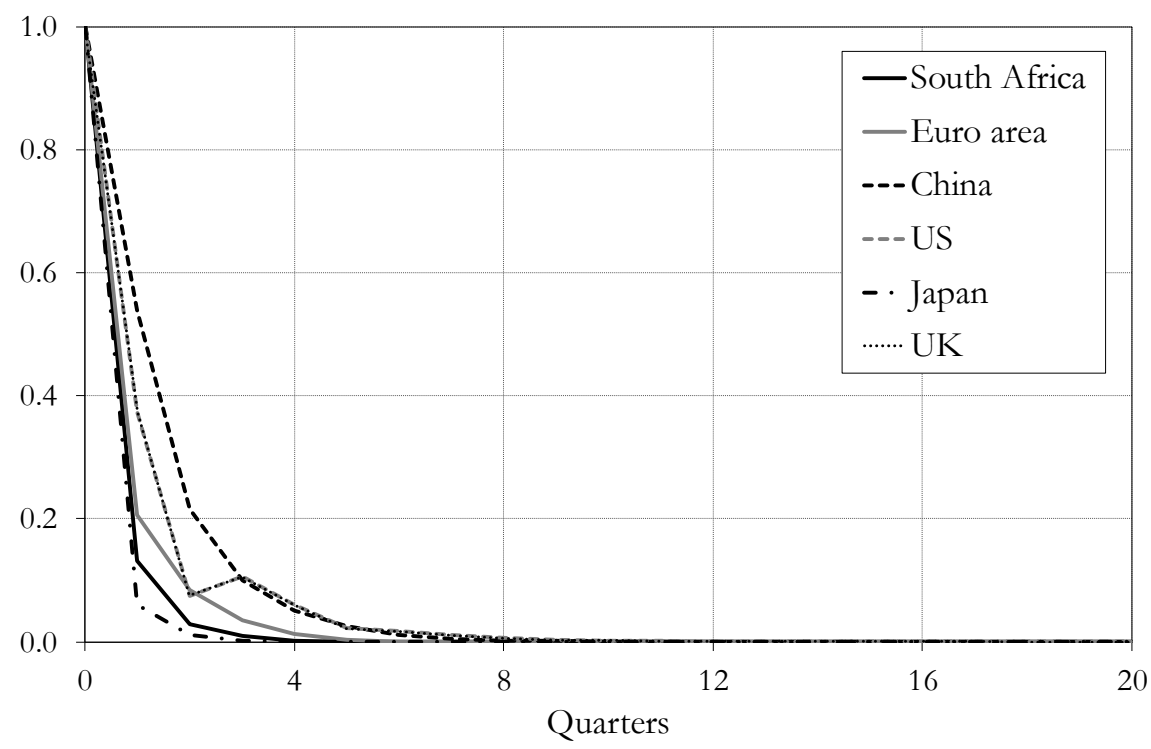

Figure 4Figure plots the PPs of the cointegrating vectors of South Africa and its three main trading partners (the Euro area, China and the US) in the small GVAR. 
Figure 4: Persistence profiles of the cointegrating vectors in the small GVAR

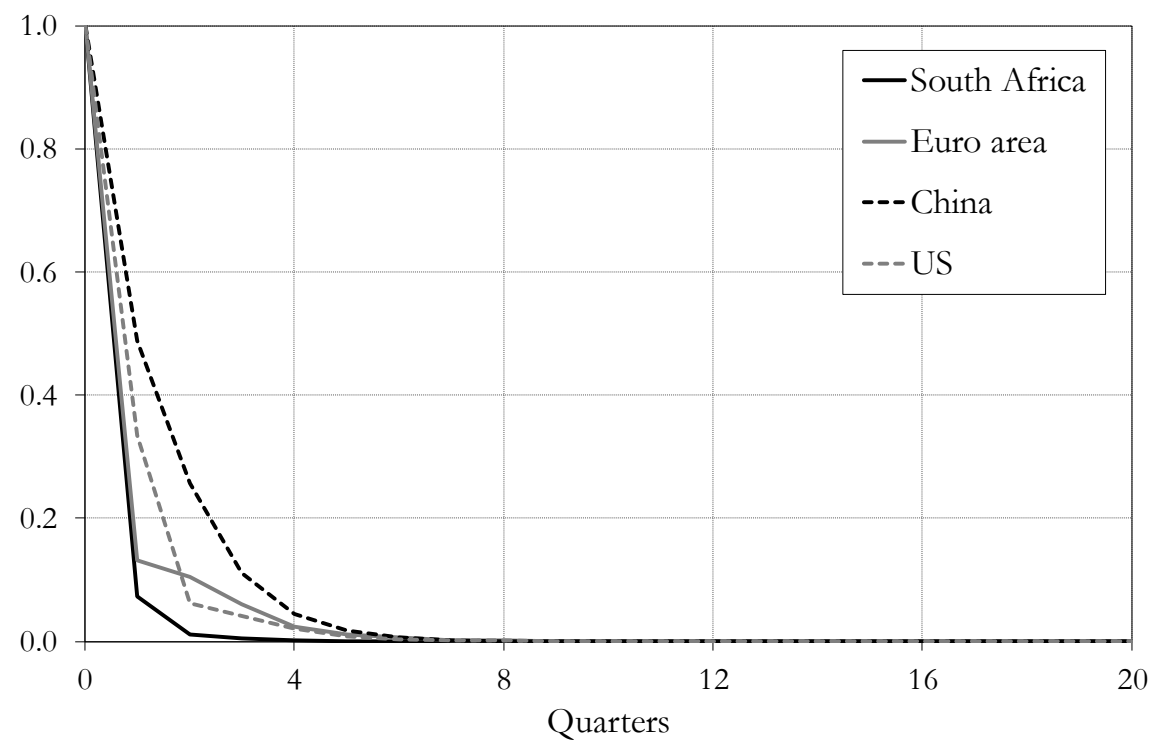

